\title{
REFLEXIONES EN TORNO A LAS PRINCIPALES POSTURAS DOĆTRINALES SOBRE LOS LÍMITES DE LA COSA JUZGADA EN EL CONTROL DE CONSTITUCIONALIDAD DE LAS LEYES
}

\author{
AUGUSTO MARTÍN DE LA VEGA \\ Universidad de Salamanca
}

SUMARIO

1. El problema de los límites de la "cosa juzgada" en la sentencia constitucional sobre la ley

2. El intento de construcción de una teoría general de los efectos de las sentencias del Tribunal Constitucional en torno al concepto de cosa juzgada: la ampliación de sus límites objetivos

3. La negación de los límites subjetivos de la cosa juzgada en la sentencia constitucional sobre la ley: la cosa juzgada "erga omnes" también para la sentencia desestimatoria

\section{EL PROBLEMA DE LOS LÍMITES DE LA "COSA JUZGADA" EN LA SENTENCIA CONSTITUCIONAL SOBRE LA LEY}

El concepto de "cosa juzgada constitucional" no ha gozado de especial fortuna en nuestra literatura jurídica. Dentro de una doctrina que cada vez es más consciente de la necesidad de ir articulando un verdadero derecho procesal constitucional $^{1}$, más allá de las inevitables polémicas acerca de su naturaleza

1. La necesidad de una sólida teoría en la que sustentar lo que Cruz Villalón denominó un "Derecho del control de constitucionalidad", La formación del sistema europeo de con- 
o de sus rasgos específicos ${ }^{2}$, lo cierto es que respecto de las sentencias sobre la constitucionalidad de la ley, el centro de atención ha seguido girando en torno a la tipología de los pronunciamientos o la modulación de los efectos temporales de los mismos.

Las razones de esta situación responden quizás a una intuición metodológica correcta: a las conocidas insuficiencias de un análisis puramente dogmático del valor de la sentencia constitucional en un campo donde el Tribunal Constitucional está llamada a tener la última palabra, se une en España una regulación positiva que, precisamente respecto a los efectos del "dictum constitucional, , se revela claramente insuficiente cuando no insatisfactoria ${ }^{3}$.

En este marco, el valor de cosa juzgada que el artículo 164 de la Constitución y posteriormente el 38.1 de la LOTC atribuyen a la sentencia sobre la ley, parecía en principio no añadir nada específico a este tipo de pronunciamientos; que se admitían generalmente como jurisdiccionales. Implicaba además sumar a las ya conocidas dificultades dogmáticas del instituto, el riesgo

trol de constitucionalidad (1918-1939), Madrid 1987, pp. 37 y ss., parece ser una constante en la doctrina española. Vid. así las permanentes llamadas a trascender el mero estudio empírico del funcionamiento del Tribunal en autores como Jiménez Campo, "Consideraciones sobre el control de constitucionalidad de la ley en el derecho español", en La jurisdicción constitucional en España, Madrid 1995, pp. 72-73, Ignacio Díez Picazo, "Reflexiones sobre el contenido y efectos de las sentencias dictadas por el Tribunal Constitucional en recursos de amparo", en La sentencia de amparo constitucional. Madrid, 1996, pp. 18-19; García Roca, "Una teoría de la sentencia en el conflicto constitucional de competencia entre entes territoriales" en La sentencia en los conflictos constitucionales, Madrid 1998, p. 14; A. Garrorena, "Artículo 164" en Comentarios a la Constitución española de 1978, (dir. O. Alzaga), Tomo XII, Madrid 1996, pp. 333 y ss., e incluso por algún procesalista como Cordón Moreno, Prólogo a la obra de Gómez Amigo La sentencia estimatoria del Recurso de Amparo, Pamplona, 1998.p. 18.

2. El primer autor español que hará referencia a la polémica sobre la pretendida autonomía del derecho procesal constitucional como "derecho constitucional concretizado" será Raúl Bocanegra en su El valor de las sentencias del Tribunal Constitucional, Madrid 1982, pp. 17-21 y 161-171. Como es sabido, esta posición parte del planteamiento de Häberle en su importante artículo "Die Eigenständigkeit das Verfassungsprozessrecht" en J.Z., 1973, pp. 451 y ss., pero puede encontrarse en obras posteriores como sus "Grundprobleme der Verfassungsgerichtbarkeit", en Verfassungsgerichtsbarkeit, Darmstadt 19765, pp. 23 y ss. o "Verfassungsprozessrecht als Konkretisiertes Verfassungsrecht" en Verfassung als offentlicher Prozess, Berlin 1978 (y 1996), pp. 631 y ss. Para una visión general del debate en Alemania, vid., K. Schlaich, Das Bundesverfassungsgericht, München, 1994, pp. 42 y 43 y E Benda,/E. Klein, Lebrbuch das Verfassungsprozessrechts, Heidelberg 1991, p. 15; ambos con múltiple bibliografía al respecto. En la doctrina italiana, el debate sobre la naturaleza del derecho procesal constitucional y sobre el grado de autonomía de la Corte frente a la norma positiva procesal ha adquirido relevancia en tiempos más recientes. Son fundamentales a este respecto las aportaciones al seminario de la Consulta celebrado en 1989, sobre Giudizio "a quo e promovimento del processo costituzionale, Milán 1990, vid. especialmente los importantes y contrapuestos artículos de Zagrebelsky, "Diritto processuale costituzionale", pp. 105 y ss. y Mezzanotte, "Processo costituzionale e forma di goberno", pp. 63 y ss. Representativo de la posición de la llamada Escuela de Pisa, de marcado tono procesalista, es el artículo de V. Angiolini "La Corte senza il "processo" o il "processo" costituzionale senza processualisti?" en La giustizia costituzionalae a una svolta, Torino 1991, pp. 20 y ss.

3. Vid., por todos, Cascajo Castro, "Artículo 164" en Comentarios a la Constitución Española, Madrid, 1988, pp. 283 y ss. 
de trasladar automáticamente conceptos procesales a una jurisdicción con peculiaridades tales que aconsejaban su tratamiento desde una óptica mucho más funcional y dinámica .

No es extraño, pues, que el estudio de en qué consista específicamente la cosa juzgada de la sentencia en el control de la ley, y por ende, de cuáles sean los límites que definen su eficacia, fuera un tema apenas abordado por los primeros comentaristas de la jurisdicción constitucionals.

Un hecho contribuirá, sin embargo, al oscurecimiento definitivo de la figura. La existencia en España de dos vías principales de impugnación de la ley, el recurso y la cuestión de inconstitucionalidad, y la confusa regulación que de sus relaciones parecían realizar los artículos 29.2 y 38.2 de la LOTC $^{6}$, conducirán a un inicial debate doctrinal centrado en torno a la compatibilidad entre ambos sistemas de impugnación.

Tal y como se desprende del proceso de elaboración de la Ley Orgánica del Tribunal, la intención del legislador al dar su redacción definitiva a los citados artículos fue variar sustancialmente el esquema previsto en el Proyecto de Ley presentado por el Gobierno. En este Proyecto, el sistema de relaciones entre las dos vías de control de la ley se articulaba sobre la prohibición sin matices de la repetición de recursos de inconstitucionalidad, junto con la posibilidad compensatoria del planteamiento sucesivo de cuestiones de inconstitucionalidad tras la desestimación de un primer recurso directo. Las modifica-

4. Así, ya muy pronto, Lucas Verdú "Política y justicia constitucionales. Consideraciones sobre la naturaleza y funciones del Tribunal Constitucional", o J. Arozamena, "El Recurso de Inconstitucionalidad", ambos en el volumen de El Tribunal Constitucional, Madrid 1981. Vid. también la sistematización de las funciones de la jurisdicción constitucional de la ley (valoración, pacificación y ordenación) que realiza Jiménez Campo en "Qué hacer con la ley inconstitucional", en La sentencia sobre la constitucionalidad de la ley, Madrid 1997, pp. 24 y ss.

5. Así el tratamiento del efecto de cosa juzgada en autores como Rubio y Aragón "La Jurisdicción Constitucional" en La Constitución española de 1978. Estudio sistemático, Madrid 1981, p. 868., Aragón, "El control de constitucionalidad en la Constitución española de 1978", en R.E.P., 1979, p. 192, Arozamena, "El Recurso de Inconstitucionalidad", op.cit., o Garrorena, "La sentencia constitucional", en $R D P, 1981$, pp. 7 y ss.

6. El art. 29.2 LOTC, dentro del Capítulo I "Disposiciones Generales" del Título II, prevé que “La desestimación, por razones de forma, de un recurso de inconstitucionalidad contra una ley, disposición o acto con fuerza de ley, no será obstáculo para que la misma ley, disposición o acto puedan ser objeto de una cuestión de inconstitucionalidad con ocasión de su aplicación en otro proceso".

El artículo 38.2 LOTC, en el Capítulo IV del mismo Título, "De la sentencia en procedimientos de inconstitucionalidad y de sus efectos", establecía en su redacción original que "las sentencias desestimatorias dictadas en recursos de inconstitucionalidad impedirán cualquier planteamiento ulterior de la cuestión en la misma vía, fundado en infracción de idéntico precepto constitucional". La Ley Orgánica 7/1999, de 21 de abril, introductora del llamado recurso en defensa de la autonomía local, supuso una modificación del artículo, que actualmente prescribe que "Las sentencias desestimatorias dictadas en recursos de inconstitucionalidad y en conflictos de defensa de la autonomía local, impedirán cualquier planteamiento ulterior de la cuestión por cualquiera de las dos vías, fundado en la misma infracción de idéntico precepto constitucional". Como puede observarse entre los dos artículos (29.2 y 38.2) se producía una "potencial antinomia" ya que sin contradecirse en sus taxativas afirmaciones, sí pueden hacerlo en lo que tácitamente parecen, a su vez, prohibir y permitir respectivamente. 
ciones introducidas por el Congreso pretendieron, en cambio, mantener la prohibición de recursos sucesivos (si bien con la precisión de que el precepto alegado fuese el mismo), pero impidiendo también el planteamiento de cualquier cuestión de inconstitucionalidad una vez desestimado el recurso sobre la misma ley, siendo este el sentido original de la introducción de la frase "por razones de forma" en el artículo 29.2 de la LOTC.

Desde un primer momento una corriente ampliamente mayoritaria de la doctrina se opuso frontalmente a esta previsión. Criterios de funcionalidad de la jurisdicción constitucional, el propio significado teleológico de la cuestión de inconstitucionalidad, y la necesidad de permitir la evolución de la jurisprudencia, llevaban a rechazar una prohibición "ad limine" de cualquier cuestión tras el recurso, tal y como parecía desprenderse de la lectura del art. 29.2 LOTC ${ }^{7}$. En consecuencia, se remarcó la contradicción de este artículo con el 38.2 y se señalaron posibles interpretaciones de ambos preceptos que salvaran la antinomia, sobre la base en la mayoría de los casos de la compatibilidad entre las dos vías de acceso ${ }^{8}$.

Como es sabido, el Tribunal Constitucional, ya desde su temprana sentencia 4/81, optará claramente por permitir el planteamiento de la cuestión de inconstitucionalidad tras una primera sentencia desestimatoria del recurso, centrándose en una interpretación estricta de la prohibición de repetición de recursos del art. 38.2 y "silenciando" jurisprudencialmente el sentido y la propia funcionalidad del art. $29.2^{9}$.

7. Vid. por todos, Rubio/Aragón, «La Jurisdicción Constitucional», op.cit., p. 870, para quienes la regulación resultaría incoherente acon la finalidad característica de la jurisdicción constitucional", ya que al impedir la capacidad de la jurisprudencia para "recrear" la Constitución, "eliminaría una de las facetas que con mayor fortuna coadyuvan a la permanencia de la Constitución y a evitar reformas excesivas..., o García de Enterría, La Constitución como norma y el Tribunal Constitucional, Madrid, 1981, pp. 139-141, quien entiende que semejante prohibición de compatibilidad consagraría un riguroso "stare decisis" que obstaculizaría "una de las funciones más importantes del Tribunal Constitucional, la interpretación evolutivaw. En términos mucho más rotundos, Bocanegra, El valor..., op. cit., pp. 77 y 255-258, que tacha el texto de inadmisible, completamente inconstitucional e incoherente".

8. Vid. los intentos de Rubio/Aragón en "La jurisdicción Constitucional", op.cit., p. 871, Almagro Nosete, Justicia constitucional, (Comentarios a la LOTC), Madrid 1980 (y 1989), pp. 135 y ss. López Guerra, "El Tribunal Constitucional y el principio de stare decisis", en El Tribunal Constitucional, v. II, Madrid, 1981, pp. 1452-1454 o Pérez Tremps, Tribunal Constitucional y Poder Judicial, Madrid, 1985, pp. 260-262. Más recientemente García Torres en La Jurisdicción Constitucional en España, op.cit., pp. 120-121.

9. Tras la sentencia 4/81, de 2 de febrero, sobre la Ley de Bases de Régimen Local, la afirmación de que tras un recurso puede interponerse una cuestión de inconstitucionalidad sobre el mismo texto es una constante en la jurisprudencia del Tribunal, algunos de los pasos iniciales pueden observarse en la STC 20/88, (impugnación del art. 15.2 de la Ley del Proceso Autonómico por el Gobierno Catalán), Autos 352/90, y 93/981, o ya claramente en la STC 9/93, (cuestión de inconstitucionalidad contra el art. 19.1 de la Ley de Reforma agraria de Andalucía) y STC 55/96, (Ley Orgánica de Regulación de Recursos sobre la objeción de conciencia).

10. Así, entre las obras sobre la materia, Fernández Segado, La jurisdicción Constitucional en España, Madrid, 1984, pp.117-118; Cano Mata, Comentarios a la LOTC, Madrid 1986, pp. 135 y ss; Montoro Puerto, Jurisdicción Constitucional y Procesos Constitucionales, T.I, Madrid 1991, 
Consagrada la compatibilidad entre los dos mecanismos de impugnación, y más dudosamente entre cuestiones sucesivas, una parte importante de la doctrina optó por obviar el problema que ello implicaba respecto al valor de cosa juzgada de la sentencia constitucional ${ }^{10}$ o bien, de manera más directa, por cuestionar abiertamente la existencia misma de este efecto ${ }^{11}$. Se seguía así

pp. 225 y ss; Caamaño Domínguez, "Los procesos de control directo" en Jurisdicción y procesos constitucionales, op.cit., pp. 69 y ss, o las aportaciones de Jiménez Campo en las obras colectivas, La jurisdicción Constitucional en España, op.cit., pp., 102 y ss; Jurisdicción ordinaria y Tribunal Constitucional, Santiago 1996, pp. 171 y ss; Los procesos constitucionales, Madrid 1991, pp. 13 y ss. o voz "sentencia constitucional" en Temas básicos de Derecho Constitucional, (coord. Manuel Aragón), Madrid, 2001, pp. 86-87.

11. El primer autor en descartar la falta de idoneidad del concepto mismo de cosa juzgada como efecto de la sentencia constitucional es probablemente García de Enterría en su Curso de Derecho Administrativo (con T.R. Fernández), Madrid 1982 (y 1997), pp. 157, al mantener que ues imposible aplicar a las sentencias desestimatorias la fuerza de cosa juzgada, que no se refiere a situaciones concretas, sino a la interpretación de la ley, materia en la que nunca una sentencia cierra el paso a una posterior interpretación distinta de la misma". Vid. también Pibernat Doménech, "La sentencia constitucional como fuente del derecho", $R D P, 1987$, pp. 62. Esta postura es llevada a sus últimas consecuencias por Martín Pageo, La cuestión de inconstitucionalidad en el proceso civil, Madrid 1990 , pp. 225 y ss., quien mantiene el principio general de la inexistencia de cosa juzgada en las sentencias desestimatorias de la cuestión de inconstitucionalidad, puesto que el art. 38.2 LOTC tan sólo prohibe la repetición de recursos. Blasco Soto, en "Reflexiones sobre la cosa juzgada en las sentencias de las cuestiones de inconstitucionalidad", REDC 1994, pp. 32 y ss., mantendrá ya la inexistencia de cosa juzgada en cualquier sentencia constitucional-desestimatoria, sea de un recurso o de una cuestión, si bien matiza que las sentencias desestimatorias intepretativas sí pueden producir un efecto positivo de cosa juzgada frente al propio Tribunal Constitucional. Por último, Rubio Llorente en su "Jurisdicción Constitucional en España" en Estudios sobre Jurisdicción Constitucional, (Rubio/Jiménez Campo), Madrid 1998, pp. 11-12, afirmará que «...la naturaleza propia de la jurisdicción constitucional lleva inevitablemente a la conclusión, coincidente con la práctica del Tribunal Constitucional, de que las sentencias desestimatorias carecen de la eficacia propia de la cosa juzgada, en cuanto que no impiden el planteamiento de nuevas cuestiones frente a los mismos preceptos legales y por infracción de los mismos preceptos constitucionales, pues de otro modo la doctrina fijada en un momento determinado quedaría petrificada y se haría imposible una evolución que adecuara la interpretación de la Constitución a la realidad social del tiempo en que ha de ser aplicada...". Y respecto a la sentencia estimatoria mantendrá que este efecto tampoco se produce "pues la imposibilidad (de reproducir el litigio) no viene de la res iudicata sino de la desaparición del objeto. De otro modo sería imposible que el legislador pudiera volver a dictar una ley de contenido idéntico o análogo... pues la res iudicata actúa sin limitación temporal".

12. La falta de cualquier mención expresa en el derecho positivo, y la inexistencia de una jurisprudencia constitucional sobre el tema dada la tardia entrada en funcionamiento de la Corte, fuerza a la literatura juridica italiana a construir un esquema de efectos de la sentencia desestimatoria basándose en sus concepciones previas sobre la jurisdicción constitucional. De ahí que el tema en sus inicios no fuera en absoluto pacífico. De todas formas muy pronto se irá consolidando una amplia corriente doctrinal, que unida por el rechazo a las primeras tesis de Calamandrei sobre el valor de interpretación auténtica de la sentencia desestimatoria, ( $L$ illegitimitá costituzionale delle leggi nel processo civile, Padova 1950) convertirá en "comunis opinio" la posibilidad de reproponer cuestiones idénticas y por tanto, la falta de cualquier efecto vinculante del pronunciamiento desestimatorio frente a jueces distintos del que elevó la cuestión. Aceptada esta postura por la Corte, desde finales de los cincuenta el debate se centró en si la eficacia de la sentencia desestimatoria en el sólo juicio "a quo" era de cosa juzgada o, como hoy se acepta muy mayoritariamente, de mera preclusión procesal. De hecho, actualmente en la doctrina italiana la expresión "giudicato costituzionale" queda referida a la prohibición de repetición de normas inconstitucionales por el legislador. Vid. por todos, dentro de una amplísima bibliografía, Ruggieri, 
curiosamente a la principal corriente dogmática italiana, cuyos presupuestos normativos, cuestión de inconstitucionalidad como mecanismo casi exclusivo de impugnación y total silencio legal respecto a los efectos de las sentencias, tanto diferían de los españoles ${ }^{12}$.

Creemos, sin embargo, que como afirmara en otro sentido Rubio Llorente, "el hecho de que la propia LOTC abra la posibilidad de que sea cuestionada de nuevo la constitucionalidad de aquellas leyes frente a las que ya se han presentado sin éxito recursos, suscita problemas que la doctrina aun no ha resuelto de manera generalmente aceptada ${ }^{13}$. O en otras palabras, que la compatibilidad abre, y no cierra, la cuestión de los límites de la cosa juzgada en la sentencia constitucional.

De hecho, una interpretación de la LOTC por el Tribunal que, en la línea posible del art. 29.2 LOTC, hubiera establecido una incompatibilidad absoluta entre ambos procedimientos, habría vanificado, "ope legis", al menos el problema de los límites subjetivos de la cosa juzgada del primer pronunciamiento constitucional.

Pero la escueta opción del Tribunal por la compatibilidad entre el recurso y la cuestión suscita el problema del alcance de dicha compatibilidad. Entender ésta como absoluta, esto es, que tras la desestimación de un recurso pueda plantearse una duda constitucional idéntica a la ya resuelta desfavorablemente, podría suponer la inexistencia del efecto de cosa juzgada del primer pronunciamiento, o bien la existencia de una cosa juzgada a cuyos límites tradicionales habría que añadir en este caso el límite de que no nos encontráramos ante el ejercicio de un mecanismo procesal distinto.

Pero es posible entender también que de la jurisprudencia del Tribunal Constitucional en torno al art. 38.2 de la LOTC tan sólo se deduce la compatibilidad genérica entre las dos vías de acceso, en atención a su respectiva función dentro del control de constitucionalidad. Así, ante el planteamiento de una cuestión de inconstitucionalidad sucesiva a una sentencia desestimatoria de un recurso, o de otra cuestión, deberían producirse los efectos previstos por la Constitución y la LOTC para toda sentencia constitucional. En este caso, el de su fuerza de cosa juzgada. Cosa juzgada que sería eficaz, como es lógico, siempre que se den los límites objetivos y subjetivos que la definen.

No se pretende aquí la ardua tarea de sistematizar estos límites, sino tan sólo la de volver a reflexionar sobre alguna de las escasas aportaciones doctrinales sobre el tema. Más allá de su valor práctico en una jurisdicción de tribunal único, lo cierto es que una mejor definición de un instituto que ya Liebman calificara en relación al proceso civil como "un poco misterioso, un

Storia di un "falso". L'efficacia de "inter partes" delle sentenze di rigetto della Corte costituzionale, Milán 1990, o Romboli "Il giudizio di costituzionalitá delle leggi in via incidentale", en Aggiornamenti in tema di processo costituzionale, (1996-1998). Turín 1999.

13. "La jurisdicción constitucional en España", op. cit., p. 11. 
monstruo del sistema" ${ }^{14}$, resultaría útil para avanzar en la siempre problemática determinación del valor del pronunciamiento constitucional.

\section{EL INTENTO DE CONSTRUCCIÓN DE UNA TEORÍA GENERAL DE LOS EFECTOS DE LAS SENTENCIAS DEL TRIBUNAL CONSTITUCIONAL EN TORNO AL CONCEPTO DE COSA JUZGADA: LA AMPLIACIÓN DE SUS LÍMITES OBJETIVOS.}

Una de las no pocas paradojas de la literatura española sobre los efectos de las sentencias del TC se encuentra en el hecho de que la primera, y hasta ahora única monografía general sobre el tema, el libro de Raúl Bocanegra, $E l$ valor de las sentencias del Tribunal Constitucional ${ }^{15}$, se centrará en el concepto de cosa juzgada para, a partir de éste, intentar explicar el complejo sistema de efectos previstos en la Constitución y en la LOTC. De este modo, la cosa juzgada, que posteriormente será objeto de una atención cuando menos no prioritaria por parte de la doctrina, que tan confusamente aparecerá en la jurisprudencia del Tribunal ${ }^{16}$, y cuya existencia será incluso puesta en duda por varios autores, iba a constituir en cambio el punto de arranque de lo que en 1982 se pretenderá, no sin cierto voluntarismo, una "dogmática española sobre el art. 164 de la Constitución."

Y es quizás por esta misma opción por la centralidad del "giudicato" constitucional por lo que el libro de Bocanegra, cita obligada en cualquier bibliografía sobre el tema, no ha sido sin embargo objeto de una atención especial a la hora de teorizar sobre los efectos de los pronunciamientos sobre la constitucionalidad de las normas con rango de ley. ${ }^{17}$

Creemos no obstante que a pesar de todos los inconvenientes con los que partía su esfuerzo sistematizador: ausencia de cualquier jurisprudencia sobre el art. 164 C. y 38 LOTC, falta de tradición dogmática o imposibilidad de prever cambios en la regulación como la del art. 5 de la LOPJ, su construcción doctrinal merece destacarse como un punto importante en la reflexión sobre el efecto de cosa juzgada de las sentencias del Alto Tribunal y sobre el esquema general de eficacia de estos mismos pronunciamientos. Por ello, antes de

14. Eficacia ed autorità della sentenza (ed altri scritti sulla cosa giudicata), Milano 1983 (ristampa), pp. III-IV.

15. Op.cit.

16. La afirmación es de uso común en la literatura sobre el tema, vid. entre otros muchos, de la Oliva, Sobre la cosa juzgada. Madrid. 1991, pp. 188-190, Jiménez Campo, "Qué hacer con la ley inconstitucional", en La sentencia sobre la constitucionalidad de la ley, op cit, p. 27, Punset; "Canón, carácter vinculante, contenido y efectos de los pronunciamientos sobre la constitucionalidad de las leyes" en La sentencia sobre la constitucionalidad...op. cit, pp. 84-85, Garrorena, "Artículo 164"...op. cit., p. 335, o Gómez Montoro "Artículo 38", en Comentarios a la Ley Orgánica del Tribunal Constitucional, (coord.. Requejo Pagés), Madrid, 2001, pg 560 y ss.

17. De Otto, "El valor de las sentencias del Tribunal Constitucional" de Raúl Bocanegra", en R.E.D.C. 1982 , pp. 334.335 
realizar una valoración crítica de sus aportaciones, puede ser útil realizar con cierto detenimiento una exposición de sus propuestas.

Bocanegra parte de reconocer que la posición y funciones del Tribunal Constitucional ${ }^{18}$ impiden considerar el problema de los efectos de sus sentencias desde una óptica meramente procesal, e implican tener en cuenta el "derecho material constitucional", realizando así una "concordancia práctica", en el línea de Hesse, entre seguridad jurídica y dinamismo hermenéutico, entre vinculatoriedad y apertura al cambio, valores estos sobre los que debe girar cualquier propuesta sobre la eficacia de las sentencias constitucionales ${ }^{19}$.

El autor dedica a continuación una atención especial al sistema de efectos consagrados en el ordenamiento alemán, centrando el problema del art. 3.1 BVerGG en tres aspectos: la posible existencia de una cosa juzgada no reconocida expresamente en la normativa constitucional o legal, la delimitación de los conceptos de vinculación, fuerza de ley y cosa juzgada, y por último la posible fuerza de ley de las sentencias desestimatorias ${ }^{20}$. Respecto al primer problema, Bocanegra, apoyándose en la jurisprudencia del TC alemán y en el sector mayoritario de la doctrina, mantiene la existencia de una cosa juzgada material como independiente del resto de los efectos de la sentencia ${ }^{21}$. Posteriormente realiza una síntesis de la caracterización del concepto de "Bindungswirkung, en la doctrina y la jurisprudencia alemana: efecto más allá del caso concreto, vinculación a los órganos constitucionales y tribunales, centra-

18. Tan sólo la aportación de Fernández Farredes, "El sistema de conflictos de competencia entre el Estado y las Comunidades Autónomas en la jurisprudencia del Tribunal Constitucional" en R.E.D.C., 1984, pg 141 y ss, prosigue la línea trazada por su compañero de especialidad. Sobre el silencio general, con ciertas referencias a la necesidad de ampliar el objeto de la cosa juzgada, vid. Montoro Puerto, Jurisdicción Constitucional y procesos constitucionales, op. cit., pp. 225 y ss. o Garrorena, quien alude a "propuestas no ayunas de justificación, aunque no me atreva a acompañarle en su extremado punto de partidà, "Art. 164"... op. cit., p. 335 . Vid. también una crítica globalmente conforme con los planteamientos de Bocanegra en de Otto, op. cit., especialmente pp. 335-334

19. Op. cit., pp. 13 y 14 y 22-29. Sobre las singularidades del derecho procesal constitucional, op. cit., pp. 161-171. El autor se inclina sin embargo por reducir los márgenes de creatividad que las tesis de un autor tan señalado como Häberle otorga al TC sobre sus normas procesales, así, "el límite de la tesis de Häberle se encuentra precisamente en el hecho real de que el constituyente a quien realmente ha atribuido la competencia para establecer los principios y desarrollos del Derecho Procesal Constitucional es al legislador ordinario y no al Tribunal Constitucional", op. cit., p. 166"

20. Op. cit., pp. 43-77

21. vid bibliografía y jurisprudencia citadas por el autor en pg 50, nota 26. Las objeciones sobre la reducida eficacia práctica del efecto de cosa juzgada para la sentencia sobre normas, en cuanto éste quedaría englobado en los efectos generales, son aún consideradas mayoritariamente como no procedentes. Así, Benda/Klein, Lebrbuch der Verfassungsprozessrechts, op cit, pg 502 y ss, Maunz/Scmidt-Bleibtreu/Klein/Usamer, Bundesverfassungsgericbtsgesetz, Art 31, München 1993, pg 13, W Löwer, "Zuständigkeiten und Verfahren des Bundesverfassungsgerichts" en Handbuch des Staats Rechts ,II , (Isensee/Kirchhof Hrsg.), Heidelberg, 1987, pg 794-795, Schlaich, Das Bundesverfassungsgerichts, op. cit., p. 272-74. Una opinión relevante y mucho más dubitativa sobre la posibilidad de distinguir en ocasiones efectivamente los tres efectos de la sentencia constitucional alemana en C. Pestalozza, Verfassungsprozessrecht, München, 1991, pg 310-11. 
lidad de las "tragende Gründe" como objeto de la vinculación y no autovinculación del tribunal de Karlsruhe. Por último, recogerá la posición general alemana sobre la "Gesetzeskraft" como reforzamiento de la vinculación, al extenderse a todas las personas físicas y jurídicas produciendo directamente para todos derechos y obligaciones ${ }^{22}$. Tal fuerza "semejante a la ley", se predicará no sólo de las sentencias estimatorias sino también de las sentencias desestimatorias, convirtiéndolas en verdaderas "declaraciones de constitucionalidad" de la ley, e impidiendo que la ley objeto de tal pronunciamiento pueda ser reexaminada por la Corte ${ }^{23}$.

La exposición del sistema de efectos alemán va a tener una importancia central en la obra de Bocanegra porque, adoptando una posición relativamente aislada en la doctrina, acogerá como correctas las críticas que a la construcción mayoritaria realiza Vogel ${ }^{24}$, críticas que son determinantes de su postura a la hora de definir, quizá mejor de redefinir, el sistema de efectos español.

Así, para Bocanegra, el entendimiento de la "Gesetzskraft" como vinculación general, y no como meros efectos "erga omnes" de la anulación de la norma, tan sólo supone de un modesto reforzamiento de la vinculación de la sentencia constitucional, en cuanto no se entiende qué "plus" sobre la obligación de la magistratura supone una vinculación a los ciudadanos exigible generalmente ante los poderes públicos. Unicamente la declaración de inconstitucionalidad de una ley que no fuera tal podría tener ese "efecto de ley" ${ }^{25}$. Mayor aún es el error de atribuir semejante fuerza a las sentencias desestimatorias o "que confirman la constitucionalidad de la ley". Esto, en palabras de Bocanegra, «supone no sólo la violación radical de los principios que presiden el sistema, facilitando la convalidación prohibida de una nulidad radical, sino también, y sobre todo, la atribución a estas sentencias no de fuerza de ley, sino pura y simplemente de fuerza constitucional ${ }^{26}$.

Más interesante es la crítica que ya en la parte española del libro el autor realiza al concepto de "Bindungswirkung". Para Bocanegra, la extensión objetiva que supone la "Bindungswirkung" hacia las "tragende Gründe", aparte de pecar de indefinición, significa un exceso frente a la finalidad última que sería deseable: evitar la repetición de conductas similares. Supone además el riesgo de un estancamiento doctrinal, de una "petrificación" de la jurisprudencia, lo que, junto con la desmesurada extensión del elemento subjetivo a todos los

22. Op. cit., pp. 66 y ss.

23. Op. cit., pp. 69-70

24. Principalmente en "Rechtskraft und Gesetzeskraft der Entscheidungen des Bundesfassungsgerichts", en Bundesverfassunggericht und Grundgesetz. Festgabe aus Anlass des 25 jäbrigen Bestehens des Bundesverfassunggerichts. I. Tubinga. 1976 Cabe destacar que es con este autor con quien, en el 1979-80, Bocanegra trabaja en Munich en la elaboración de esta monografia.

25. Op. cit., pp. 71 y ss.

26. Op. p. 77 , donde se subraya la circunstancia, frente al sistema español, de que la presentación del recurso directo no tiene un plazo determinado de presentación. 
poderes públicos, implicaría poner en peligro al otro gran pilar del sistema: la necesaria apertura de la jurisdicción constitucional hacia los cambios sociales y políticos ${ }^{27}$. En definitiva, "estos resultados jurisprudenciales son absolutamente insatisfactorios por excesivos, y en ningún caso quedan compensados por la genérica apelación a la no autovinculación del Tribunalı²8.

27. La posición doctrinal mayoritaria, y la propia jurisprudencia del TC alemán, siempre han remarcado, no obstante, los límites a la vinculación a las «tragende Gründe" de los pronunciamientos constitucionales, vid, por todos, Maunz/Schmidt-Bleibtreu, op. cit., p. 15 y ss, donde se insiste en un concepto restrictivo de los mismos, "vinculación a las causas de la decisión cuando el propio Tribunal quiera abiertamente conceder a ciertos razonamientos un carácter regulativo y los fundamenta detalladamente", y un límite por su objeto: tan sólo aquellos que versen sobre la interpretación de la constitución. Es cierto, sin embargo, que con posterioridad a la obra de Bocanegra y a la postura de Vogel, la actitud crítica hacia la inclusión de dichas "tragende Gründe" en el efecto vinculante ha ido adquiriendo un mayor eco en la doctrina, vid por todos, G. Stricker, "Subjetive und objetive Grenzen der Entscheidungen gemass art. 31 Abs. 1 BverfGG" en D.Ö.V. 1995, pg 982 y ss. Son significativas también las reticencias aparecidas en obras de amplia difusión, vid Löwer "Zuständigkeiten und...", op. cit., p. 796 y ss, donde, tras señalar que todos los argumentos que se suelen dirigir contra una vinculación estricta a la jurisprudencia del Tribunal Supremo son válidas también para una vinculación normativa a las "tragende Gründe" del Tribunal Constitucional, mantiene que " la ampliación del art. 31.1 BverfGG, que sólo habla de la vinculación de la decisión $-y$ no sobre sus fundamentos- es por ello mismo una vulneración de los límites funcionales de la jurisdicción constitucional", op. cit pg 797, apuntando seguidamente, en nota a pie de página, que ésta podría ser ya actualmente la opinión mayoritaria de la doctrina. K. Schlaich, en su Das Bundesverfassungsgericbts, op cit, pg 277-283, sintetiza las razones del rechazo a la extensión del concepto de vinculación a los fundamentos jurídicos. En primer lugar la propia dificultad de determinar el objeto de la vinculación. No sólo para distinguir entre "obiter dicta" y razonamiento fundamental, y para saber quién realiza la distinción, sino para aclarar qué sean las "tragende Gründe", si " cuestiones de lógica imprescindibles para el razonamiento" o bien " cuestiones de valoración constitucional reflexivamente fundadas". En segundo lugar existiría una cierta contradicción entre la insistencia en el carácter abierto del derecho constitucional junto con una comprensión dinámica del ordenamiento, y admitir una interpretación vinculante que iría petrificando (cimentando) cada vez más ese derecho constitucional. Se trata de la conocida crítica a la "canonización" de las valoraciones de la sentencia. Un riesgo de inmovilidad no salvado por la falta de autovinculación del TC, en çuanto los tribunales inferiores, aceptando la fuerza de su jurisprudencia, dejan de elevar cuestiones y dificultan el propio cambio del órgano. Se priva en definitiva al Alto Tribunal de un "elixir vital" de toda jurisdicción suprema: la crítica de los órganos inferiores, la polémica que permite la autorreflexión. En tercer lugar esta sobrevaloración de la jurisprudencia contribuye a que el Tribunal se vaya alejando cada vez más de la interpretación de los contenidos concretos de las singulares normas constitucionales para atenerse a concepciones jurídicas generales (equidad, proporcionalidad, no arbitrariedad etc.). Por último, no se puede olvidar que falta una previsión normativa expresa que autorice esa fuerza vinculante de los razonamientos considerada "judicialmente revolucionaria"

28. Op. cit., p. 116. Como ejemplo de cierto "apriorismo" del autor sobre el tema, valga la lista de consecuencias prácticas en que sintetiza el autor el efecto de la "Bindungswirkung" según la jurisprudencia alemana: imposibilidad de otros Länder de mantener comportamientos juzgados como "no leales" en otro Land por el TC, imposibilidad de aprobar por el Parlamento una ley de idéntico contenido que la declarada inconstitucional, vinculación a la interpretación acogida por el Tribunal para salvar la constitucionalidad de la ley, plazo al parlamento para aprobar normativas necesarias desde el punto de vista constitucional, imposibilidad de sucesivas cuestiones sobre la ley declarada constitucional. Salvo, en todo caso, las dos últimas consecuencias, resulta difícil afirmar sin más que para juzgar excesivos tales resultados "no se necesita en este momento de mayores consideraciones que las que se deducen de la simple lectura de las afirmaciones juris-
prudenciales", op. cit., p. 116. 
Frente a todo ello, Bocanegra acoge la tesis sostenida por Vogel para el sistema alemán: la finalidad última que debe perseguirse al asegurar un grado de estabilidad a la sentencia constitucional es la de evitar la repetición de actos. Para ello es suficiente el concepto procesal de cosa juzgada, que evita los múltiples inconvenientes de la "Bindungswirkung", ahora bien, por esto mismo, es necesario realizar un "ajuste constitucional" de dicho concepto, redefiniendo su ámbito objetivo ${ }^{29}$. Así, si la cosa juzgada esta limitada subjetivamente a las partes procesales, entendiendo por tales las que pudieron personarse, los límites objetivos de la cosa juzgada vendrán determinados por la "konkrete Entscheidungsnorm" (concreta norma de la sentencia), que es definida por Vogel como «aquella consideración o afirmación jurídica que fundamenta el fallo, y que está formulada exactamente de tál modo general que fuera de la decisión adoptada en el caso concreto, resultaría de ella una decisión igual en casos iguales " ${ }^{30}$. Con tal "extensión objetiva" del concepto clásico de cosa juzgada predicable de todo tipo de sentencias constitucionales, se logrará aquella "concordancia práctica" entre estabilidad de la decisión, es decir prohibición de la repetición de juicios idénticos, y apertura de la jurisprudencia a nuevos cambios, reduciendo así el excesivo ámbito objetivo y subjetivo del concepto de "Bindungswirkung," ${ }^{31}$.

Dejando aquí aparte el esfuerzo realizado por el catedrático de derecho administrativo para adecuar el concepto acogido de cosa juzgada al proceso contencioso administrativo, conviene subrayar que Bocanegra pretende desde un principio establecer un sistema general explicativo de los efectos de las sentencias del Tribunal Constitucional en todo tipo de procesos. Para ello, comenzará aplicando su esquema conceptual a los conflictos constituciona$l \mathrm{e}^{32}$, continuará con los procedimientos de inconstitucionalidad de la ley, refi-

29. Op.cit., pp. 112 a 118 entre otros muchos.

30. Op. cit., p. 205. Para no olvidar la relación que tal definición guarda con la finalidad del "Widerholenverboten", basta observar la definición que en relación al proceso civil da también Vogel "el concreto mandato infringido y la declaración de que el mismo caso volvería a infringirlo". op. cit., pp. 152-153.

31. Vid., entre otros muchos, op. cit., p. 108. No son extraños a estos planteamientos los ya realizados por autores como A. Zeuner, "Uber di Geltungsdauer der Entscheidungen des Bundesverfassungsgerichts und die Möglichkeiten späterer abweichender Entscheidungen" en $D O ̈ V$, 1955, o más recientemente.S. Detterbeck, "Normenwiederholungsverbote aufgrund normverwerfender Entscheidungen des B undesverfasungsgerichts?, en $A \ddot{O} R, 1991$.

32. La orientación, podría hablarse de reducción, de la finalidad de los efectos de la sentencia constitucional al objetivo de la "Widerholenverboten" es especialmente atrayente en el campo de los conflictos constitucionales, de los que Bocanegra acentuará su perspectiva subjetiva. Si la sentencia tiene como contenido la declaración de inconstitucionalidad o no de la norma y la determinación de la competencia del sujeto procesal, aunque ésta última quede clara, se hace necesaria la extensión del límite objetivo de la cosa juzgada más allá del fallo si se quiere evitar la repetición de la medida. El ámbito subjetivo de la cosa juzgada de la STC corresponderá siempre a todos los posibles legitimados. Es aquí donde Bocanegra encuentra un problema de legitimación que "salva" con la apelación al art. 64.4 de la LOTC. Para la sentencia desestimatoria la finalidad no puede ser, obviamente, la prohibición de repetición sino la de que no vuelvan a ser discutidas actuaciones de contenido idéntico a la medida declarada constitucional, op. cit., pp. 
riéndose por último, si bien es cierto que muy sumariamente, a las sentencias de los recursos de amparo, al control de constitucionalidad de los tratados internacionales y a los pronunciamientos del entonces vigente recurso previo de inconstitucionalidad ${ }^{33}$. Independientemente de las reflexiones que puedan hacerse sobre semejante sistemática, lo cierto es que para nuestro tema el aspecto central del estudio viene delimitado por sus consideraciones sobre las sentencias en los procedimientos de control de normas con rango de ley ${ }^{34}$.

Es en este aspecto donde, al trasladar al sistema español la minoritaria visión de Vogel, puede decirse con Ignacio de Otto que "la LOTC se muestra más germanófila que su crítico, ${ }^{35}$. La peculiaridad del esfuerzo de Bocanegra consistirá sin embargo en el hecho de que esta traslación no va a responder a ún mero "mimetismo" comparatista sino que obedecerá a exigencias del todo particulares de la regulación del sistema español.

A lo largo de toda la monografía es relativamente sencillo percibir el principal problema con el que Bocanegra pretende enfrentarse: encontrar una dogmática de los efectos de las sentencias que permita al Tribunal Constitucional replantearse sus anteriores decisiones, cumpliendo así con las exigencias de apertura y evolución jurisprudencial inherentes a todo sistema concentrado de control de constitucionalidad. O en términos más concretos, definir la eficacia de los pronunciamientos en el recurso y la cuestión de forma tal que no se impida el posterior replanteamiento de la constitucionalidad de la ley tras una primera sentencia del Tribunal. Y todo ello salvaguardando un mínimo de estabilidad que permita evitar inútiles repeticiones de juicios ya realizados ${ }^{36}$.

179 a 223. Cabe destacar la equiparación que se realiza de los efectos de la sentencia de todo tipo de conflictos (competenciales positivos y negativos, y de atribuciones), de los que una regulación normativa distinta "no alcanza, sin embargo a desvirtuar la igual significación de todos ellos", op. cit., p. 192. En los supuestos de sentencia estimatoria por otra parte, el paralelismo con los problemas de la jurisdicción contencioso administrativa es acentuado expresamente, (vid., por ejemplo, p. 198). Las consideraciones sobre la preferencia del límite objetivo de la "concreta decisión" y no de la "Bindungsrwirkung", pp. 202 y ss., serán analizadas más adelante, puesto que sirven para esclarecer parte de la postura que subyace en el planteamiento de Bocanegra también sobre el control de las leyes. Curiosamente el autor volverá a pronunciarse sobre el tema de los efectos de las sentencias constitucionales tan sólo en una ocasión, en su artículo "Sobre el alcance objetivo de las sentencias del Tribunal Constitucional", en Estudios sobre la Constitución española. Homenaje al profesor García de Enterría. T. I. Madrid. 1991, pp. 509 y ss, y ya en esta fecha reafirmará vigorosamente, y sin ninguna rectificación, las mismas tesis que en 1982 al inicio de la experiencia de justicia constitucional. El ámbito escogido para la "defensa" no deja de ser sin embargo significativo: los conflictos constitucionales (y no los procedimientos de control de leyes) y dentro de ellos, el "alcance objetivo", que ahora llamará de "las sentencias del Tribunal Constitucional" (y no el límite subjetivo de la cosa juzgada de dichas sentencias). Para Bocanegra, en definitiva, "la inutilidad de la introducción del difuso concepto de la "Bindungsrwirkung" como noción explicativa del valor de las sentencias del Tribunal Constitucional, al margen de su más que dudosa constitucionalidad, me parece cada vez más clara", op. cit., p. 509.

33. Op. cit., pp. 280-281.

34. Pp. 225-278.

35. De Otto, op. cit., p. 334.

36. Op. cit., pp. $65-66$ y 83 y ss., entre otras muchas. 
Para cumplir semejante objetivo el autor parte de la necesidad de reconocer a las sentencias del Tribunal Constitucional unos efectos que, en aras de su labor pacificadora e interpretativa, superen a los de las sentencias ordinarias. Tales efectos se articularán sin embargo en torno al concepto de cosa juzgada ya anteriormente descrito, lo que implica, "ad radice", una descalificación de la posible aplicación al sistema español del concepto de "Bindungswirkung" alemán. Para el autor, tal concepto no sólo es dudosamente constitucional ${ }^{37}$, sino que es totalmente innecesario en cuanto sus efectos pueden ser perfectamente cubiertos con la eficacia de la cosa juzgada ampliada objetivamente ${ }^{38}$. Se ratificaría así la configuración de la "res iudicata" como elemento absolutamente "central" en la regulación constitucional española de los efectos de las sentencias del Tribunal Constitucional.

La ampliación del límite objetivo de la cosa juzgada se encontrará al servicio de una general exigencia de "Widerholenverboten". El concepto de "concreta norma de la decisión" permitirá establecer con claridad un núcleo de resistencia y estabilidad de la sentencia. El límite objetivo "tradicional" del "giudicato", el estricto tenor del "fallo", sería así incapaz de evitar la repetición de normas idénticas por parte del legislador tras la sentencia estimatoria ${ }^{39}$ y el replanteamiento de dudas de inconstitucionalidad en nada diferentes a las rechazadas en la sentencia desestimatoria de la $\operatorname{Corte}^{40}$. Por otra parte, una aplicación aquí del concepto de "Bindungrwirkung", con su inclusión de las "tragende Gründe", supondría una extensión excesiva del ámbito de lo "inamovible" y acarrearía una petrificación de los "principios jurídico constitucionales" por cuya permanente adaptación el Tribunal debe velar ${ }^{41}$.

Será también el concepto de cosa juzgada el que permitirá al autor construir un sistema de efectos que responda a la segunda exigencia del sistema, el necesario dinamismo en la interpretación constitucional. Es este sin duda uno de los elementos centrales de su teoría, aún cuando la relativa novedad en la ampliación del elemento objetivo de la cosa juzgada haya generalmente oscurecido la relevancia de la aportación de Bocanegra en este aspecto. De hecho, el administrativista encontrará en los tradicionales límites subjetivos del instituto la respuesta al problema de la reproponibilidad de los asuntos ante el Tribunal Constitucional.

37. La descalificación del concepto de "Bindungswirkung", sobre la que posteriormente volveremos, es constante a los largo del trabajo, y de él se llega a afirmar que "viene en absoluto desmentida por el texto constitucional", op. cit., p. 82.

38. Op. cit., p. 83.

39. Op. cit., pp. 235-239; vid. también "Sobre el alcance....", op cit., p. 514.

40. Para el autor, la sentencia desestimatoria puede «establecer expresamente la validez de la ley", o "simplemente rechazar el recurso, de donde la constitucionalidad de la norma viene indirectamente afirmada". La inclusión de la "norma concreta de la decisión" sirve aquí para constatar "la constitucionalidad de la prescripción legal sometida a examen, así como la de todas las que de la misma clase pudieran dictarse en el futuro". op. cit., p. 249.

41. Vid., entre otras muchas, p. 111. 
Para ello se parte de la consideración de que los efectos generales previstos en el art. 164 CE y 38.1 LOTC tan sólo son predicables de las sentencias que declaran la inconstitucionalidad de la ley ${ }^{42}$. La negación del efecto "erga omnes" que pudiera tener cualquier sentencia desestimatoria se convierte así en un elemento absolutamente necesario en la teoría del autor, en cuanto afecta "a un aspecto sustancial de este trabajo, como es la más genérica cuestión de la posibilidad de que el Tribunal Constitucional pueda volver a dictar una sentencia, (incluso anulatoria) examinando una norma cuya conformidad con la Constitución ha sido precisamente afirmada" "43. La hipotética atribución de estos efectos generales también a las sentencias desestimatorias supondría "que una ley confirmada en su constitucionalidad por una sentencia del Tribunal Constitucional no podría volver nunca a ser puesta en cuestión -salvo por el legislador-... y esa sentencia dispondría de un valor superior al de las leyes mismas, un valor constitucional totalmente inaceptable ${ }^{44}$.

Es por ello por lo que Bocanegra realiza una demoledora crítica de los artículos 38.2 y 29.2 de la LOTC, donde cree encontrar una apuesta por la atribución de una cosa juzgada sin límites subjetivos a los pronunciamientos que desestimen el recurso o la cuestión..$^{45}$. Todo ello con una evidente finalidad: si las sentencias desestimatorias no producen efectos generales, entonces "los límites subjetivos que habrán de ser atendidos serán los derivados de los efec-

42. Vid. pp. 253 y ss. En realidad, en una dura crítica de la fórmula utilizada por el art. 164 de la CE, Bocanegra reduce los efectos generales sólo a las sentencias estimatorias, o de mera inconstitucionalidad, de los procedimientos de inconstitucionalidad de las leyes, y a aquellas sentencias de los conflictos de competencias o de atribuciones que puedan implicar la anulación de una norma de carácter general, op. cit., pp. 86 y ss. Con ello, descartada la "Bindungsrwirkung", el esquema de efectos previsto en el ordenamiento queda reducido a la cosa juzgada y a la "consecuencia lógica del sisteman: las sentencias que declaren la inconstitucionalidad de normas con fuerza de ley tendrán efectos "erga omnes". Consecuencia "ógica" en cuanto inevitable correlato del sistema concentrado kelseniano, op. cit., p. 32.

43. Op. cit., p. 231.

44. Op. cit., p. 254.

45. Inaugura así como vimos Bocanegra, junto con Enterría, La Constitución como norma.., op. cit., pp. 139-141 y Rubio /Aragón "La jurisdicción constitucional", op. cit., p. 870, la larga lista doctrinal de descalificaciones a la regulación de la LOTC en esta materia. Los argumentos del autor no son por otra parte en exceso distintos, en cuanto señala su disconformidad con el art. 164.1 CE, que debería reservar claramente el efecto "erga omnes" para las sentencias "que declaren la inconstitucionalidad de una ley", o cuando subraya que en todo caso "este valor cuasi legislativo" correspondería, en una interpretación estricta, tan sólo a las sentencias desestimatorias de los recursos de inconstitucionalidad, y ello únicamente en relación con una eventual segunda cuestión de inconstitucionalidad y no de otros recursos de inconstitucionalidad. Más innovador es su razonamiento sobre la incompatibilidad de tal lectura con la existencia de la "autocuestión" y con la regulación del antiguo recurso previo, que preveía la no preclusión de una posible impugnación de la ley en un momento posterior a la entrada en vigor de la norma cuestionada. Lo verdaderamente peculiar de la postura de Bocanegra es sin embargo el duro tono de su crítica, así por ejemplo calificará a los art. 29.2 y 38.2 LOTC como uinadmisibles con arreglo a los principios generales ya expuestos, completamente inconstitucionales e incoherentes en su concreta regulación con la economía de la propia LOTC", op. cit., pp. 257-8. 
tos de la cosa juzgada" ${ }^{46}$. Es decir, tan sólo los legitimados, y para el autor, utilizando un concepto amplio, aquellos que pudieron participar en el juicio si lo hubieran deseado, se encuentran sometidos al efecto vinculante de la cosa juzgada de la sentencia. Ni los jueces ni los ciudadanos, salvo que estos últimos hayan participado en el juicio "a quo" que dio origen a la primera sentencia, son partes en el juicio constitucional, y por ello tendrán encomendada "la función capital de activar el control constante y permanente de la constitucionalidad de las leyes, que, como una de sus más destacadas funciones, debe cumplir el órgano de justicia constitucional ${ }^{47}$. Con ello se consigue la buscada posibilidad de replanteamiento y se cierra la demostración de la utilidad del concepto de cosa juzgada para definir, a salvo la fuerza "erga omnes" de las sentencias estimatorias, el sistema de efectos de los pronunciamientos constitucionales.

La obra de Bocanegra implica pues una importante contribución al estudio de los efectos de la sentencia constitucional. El relieve dado a la figura de la cosa juzgada, en un intento serio de definir desde la perspectiva del derecho procesal constitucional un instituto jurídico consagrado en el art. 164 de la Constitución, sigue siendo sugerente en un panorama donde dicho efecto no pasará de ser una mera referencia obligada, más o menos incómoda, en la literatura posterior. Coincidimos con él en la que quizás sea una de las aportaciones claves del trabajo, la concreción de la finalidad del instituto de la ures iudicata" en la prohibición de repetición de juicios idénticos. Como lúcidamente señala una vez más de Otto $^{48}$, la consideración material de las funciones del Tribunal, aquí de su función pacificadora, a la hora de configurar la cosa juzgada constitucional es el rasgo que contribuye a afianzar la obra en la órbita del derecho constitucional "también desde el punto de vista metodológico".

Todo esto no es óbice sin embargo para que, como no podía ser de otra forma, pueda discreparse en algún punto del planteamiento del autor. En primer lugar, y en un plano general, parece necesario subrayar que, si bien es cierto que la cosa juzgada es un efecto importante del de la sentencia constitucional, no parece necesario reducir en la práctica su complejo sistema de efectos a la cosa juzgada. Y ello porque aunque la función pacificadora, y por tanto la "prohibición de repetición", sea la finalidad propia del "giudicato" constitucional, se corre el riesgo de caer en una perspectiva seriamente reduccionista de las funciones del Tribunal si esta finalidad se convierte en objetivo prioritario y casi único del órgano, en correlato con la exclusividad del efecto de cosa juzgada. Y consecuencia de esta forma de ver las cosas es la denigración del concepto de "Bindungswirkung" o vinculación a los poderes públi-

46. Op. cit., p. 261

47. Op. cit., pp. 267-268. Bocanegra conecta semejante posibilidad de elevación de la CI con el derecho fundamental a la tutela judicial efectiva, en contra de la constante, y ciertamente posterior, jurisprudencia constitucional.

48. Op. cit., p. 333. 
cos, y una posición de fondo que no deja de implicar una minusvaloración del papel del TC en la interpretación constitucional y en su relación con la magistratura.

Bocanegra comienza su trabajo destacando las peculiaridades del Tribunal en orden a sus especiales cometidos, que concreta en su función pacificadora y en sus "singulares deberes de protección e interpretación de la Constitución ${ }^{49}$. Pero inmediatamente plantea el problema de los efectos de sus pronunciamientos en torno a "los criterios materiales para la determinación del grado de fijación o de definitividad de los mismos "50, es decir en torno a una "Festschreibung" que, en su juego entre fijeza y cambio, responde mucho más a la determinación de una eficacia correcta en su labor pacificadora que a su función de intérprete constitucional. De hecho, se produce una reducción del problema interpretativo al mero problema pacificador. No en vano Bocanegra mantiene que la función de intérprete supremo de la Constitución "la cubre justamente el Tribunal Constitucional por medio de la decisión y la definitiva terminación del concreto litigio constitucional, ${ }^{51}$, y lo que es más, que el aseguramiento de su preeminencia interpretativa, cubierta en la sentencia estimatoria por el efecto general, en la sentencia desestimatoria "no necesita a mi juicio ningún mecanismo jurídico especial (como la "vinculación de los poderes públicos" incluidos los tribunales y los jueces) que vaya más allá de entender que los tribunales y los jueces deben considerar la sentencia constitucional confirmatoria como vinculante $u$ obligatoria entre aquellos a quienes subjetivamente alcanza su eficacia" (las partes en el juicio "a quo"). Añadiendo "y este es justamente un efecto de la cosa juzgada, el efecto de "Tatbestandswirkung, ${ }^{52}$.

Reducida la función interpretativa a la "definitiva terminación del litigio", esto es, a la función pacificadora, todo el problema parece reconducirse a encontrar el grado de "Festschreibung" que cumpla tal finalidad. Para ello han de buscarse institutos jurídicos que al limitarse a la prohibición de repetición de la actuación ("widerholungverboten") cumplan a la vez las exigencias de estabilidad y de apertura necesarias, puesto que más allá de la prohibición de repetición "se pone en cuestión la capacidad de cambio de la constitución "53.

49. Op: cit., pp. 17-18. Significativamente, concreta esta función pacificadora en "crear claridad jurídica, eliminar material litigioso e impedir la repetición sucesiva de las mismas controversias, en la misma línea Geiger, "Die Grenzen der Bindung verfassunggerichtlicher Entscheidungen (art. 31. Ab 1 BverfGG) en $N . J . W, 1954$.

50. Op. cit., p. 22.

51. Op. cit., p. 111. O en parecidos términos, “la función de supremo intérprete constitucional es cabalmente cumplida por medio de la emisión de la sentencia y la eliminación del conflicto concreto" op. cit., p. 203.

52. Op. cit., p. 271.

53. Op. cit., p. 66. Semejante finalidad es expresamente atribuida a la sentencia del conflicto constitucional, op. cit., pp. 198-199, a la sentencia estimatoria del control de normas legales, en cuanto destinada a evitar una nueva ley repetición de la anterior, op. cit., p. 235, y a la sentencia de anulación del contencioso administrativo, quizás donde mejor se aprecia hasta qué 
Llegados a este punto, el autor realiza una severa crítica del concepto de "Bindungswirkung ${ }^{54}$ en cuanto su extensión a los "tragende Gründe" y su vinculación a los poderes públicos suponen una peligrosa "petrificación" del sistema de justicia constitucional. Y a continuación otorgará a la institución una finalidad concreta: la prohibición de repetición, para, acto seguido, descalificarla en cuanto "excesiva" en relación con esa misma finalidad..$^{55} \mathrm{El}$ paso siguiente es previsible: si la finalidad de la "Bindungswirkung" es la eliminación de los concretos conflictos jurídico-constitucionales planteados, "esa es claramente, también, función del valor de cosa juzgada, y a través de él puede ser cubierta " ${ }^{56}$.

Con este planteamiento sin embargo parece olvidarse precisamente que, en la doctrina alemana, la finalidad de la "Bindungswirkung" no es tan sólo pacificadora sino ante todo interpretativa, en cuanto instrumento para asegurar la conformidad de los poderes públicos a los dictados constitucionales a través de su vinculación a la interpretación que realiza el Tribunal de Karlsruhe, consagrando con ello una "supremacía hermeneútica" a cuyo objetivo responde la especial configuración del instituto. ${ }^{57}$ Lejos pues de una única pretensión de determinar el "concreto conflicto constitucional" evitando la repetición del mismo. Así, en cierto modo, se produce una descalificación de la institución por ser ineficaz para cumplir una finalidad que realmente no persigue, o al menos, no prioritariamente. ${ }^{58}$

Pero independientemente del complejo problema que el concepto recogido en el art. 31.1 BVGG plantea en el ordenamiento alemán, lo que resulta

punto Bocanegra centra en esta prohibición el problema de los efectos de las sentencias, y quizas también hasta dónde una visión correcta para la JC-A, no deja de pecar de graves insuficiencias si es aplicada miméticamente al "contencioso constitucional", op. cit., pp. 130, 134-136, y 148 especialmente. Por otra parte, algunas consideraciones marginales en la obra acerca de la importancia de las motivaciones del Alto Tribunal no logran atenuar el grado de reducción a la función pacificadora de esta visión. vid p. 200.

54. La concreta redacción del texto es "si en el fondo, pues, la finalidad de una extensión de la vinculación de las sentencias constitucionales a alguna parte de los motivos del fallo es...". Por el contexto, es inequívoco que el autor se está refiriendo a la "Bindungswirkung".

55. Op. cit., p. 204.

56. Op. cit., p. 204, también 203 o 122.

57. Aun si olvidar que la opción por la inclusión de las "tragende Gründe" en el campo de la Bindungswwirkung fue también defendida como un modo de pacificar hacia el futuro las hipotéticas controversias en torno a la interpretación de la constitución, así vid inicialmente Geiger, Die Grenzen...op. cit., p. 1057 y ss. El tema guarda relación con la inicial polémica sobre la posibilidad de repetición de normas similares a las anuladas por el Tribunal. Sobre la divergencia entre las dos "Salas" del Tribunal Constitucional aleman, y las implicaciones del problema para la dogmática de la jurisdicción constitucional, vid, por todos, Schlaich, op. cit pg 277 y ss.. Para una clara relación entre poder interpretativo de la constitución y vinculación a los fiundamentos, vid E. Friesenhan "Zum inhalt und zur Wirkung der Entscheidungen des deutschen Bundesverfassungsgerichtes" en Scritti in onore di Gaspere Ambrosini, I Milano, pg 699 y ss.. La postura clásica al respecto, con abundante bibliografía en Schlaich, op. cit., pg 277 y ss, quien sin embargo, como vimos, no la comparte en su totalidad. Vid también Löwer "Zuständigkeiten...." op. cit., p. 795-7999 y Maunz/Schindt-Bleibtreu, op. cit., p. 15 y ss.

58. Otra cosa es que en el planteamiento de Vogel no dejen de estar estrechamente implicados la asignación de esta finalidad y su pretendida sustitución por el concepto de cosa juzgada. 
más significativo para nuestro estudio son las consecuencias de su translación al sistema de efectos español. Aplicando el silogismo anteriormente criticado, Bocanegra llega a la conclusión de que la "Bindungswirkung" no se da en nuestro ordenamiento " porque la constitución no lo permite y porque buena parte de los efectos que este concepto describe pueden ser perfectamente cubiertos ...justamente por el concepto de cosa juzgada" 59 .

La trascendencia de este argumento es evidente por dos razones: en primer lugar porque implica la necesidad de buscar un concepto amplio de cosa juzgada que cumpla la función pacificadora que el autor básicamente asigna al concepto de "Bindungswirkung". En un segundo aspecto porque, dado que la noción alemana se demuestra ineficaz, por excesiva, para cumplir esa función, y lo que es más, "innecesaria" al existir la institución de la cosa juzgada, tal efecto es como vimos rigurosamente eliminado del sistema de efectos español ${ }^{60}$. De este modo se completa la identificación del concepto dogmático de "Bindungswirkung" de la doctrina alemana, con la precisión del efecto "Vinculante" para los poderes públicos que consagra nuestro art. 38.1 de la LOTC. Pero dejando aparte que el origen histórico de la redacción del artículo 38.1 de la LOTC pueda encontrarse en un "afán comparatista", lo cierto es que desde un punto de vista dogmático la exacta equiparación entre ambos conceptos no es una estricta exigencia lógica.

Se fuerza así una "relectura" de nuestro sistema normativo ya de por si excesiva $^{61}$, que conduce a la afirmación de que en el texto constitucional la cosa juzgada ocupa "un papel central en el esquema de efectos" y que este mismo diseño del art. 164 de la Constitución «es un sistema cerrado sobre sí mismo, en el que no tiene fácil cabida cualquier otra figura jurídica fuera de las señaladas (cosa juzgada y efectos generales) :que ellas mismas deben de ser suficientes para cubrir todos los casos que se presenten es un imperativo constitucional. ${ }^{62}$. Se termina negando, pues, cualquier virtualidad a un efecto vinculante para los poderes públicos que se encuentra expresamente recogido en la normativa sobre la eficacia de las sentencias y que será literalmente incorporado y utilizado por la jurisprudencia del TC. Con ello quizás también se pierda una ocasión para intentar construir un concepto propio de "vinculación a los poderes públicos", que, sin impedir por exceso las funciones paci-

59. Op. cit., pp. 82 y 122.

60. Vid, entre otras muchas, pp. 82, 86, 104, donde se afirma que el término utilizado por la LOTC "supone la aceptación de una terminología hueca, no de un concepto. Esta expresión carece en realidad de contenido real, de virtualidad operativa, una frase gramatical sin contenido jurídico alguno.", p. 118 "rechaza con suficiente fundamento, además de por inconstitucional, por inútil e inadecuada la figura de la "Bindungswirkung" en nuestro ordenamiento", o p. 117 " interdicción por nuestra norma fundamental de la categoría de "Bindungswirkung" ".

61. En distintos lugares se califica al art. 161.1 de la C. de "inútil", en la misma línea que al art. 164. C. en cuanto a su referencia a la limitación de efectos generales y a la publicación de las sentencias. Parecidos calificativos reciben los artículos 40.2, 13, 61:3 o 32 de la LOTC, por no hablar, obviamente, del propio art. 38.1.

62. Op. cit., p. 89. 
ficadoras propias de la cosa juzgada, sí sirva en cambio para atender a otro de los rasgos propios del TC, su condición de "intérprete supremo" de la Constitución.

En cuanto a su concepción del efecto de cosa juzgada, creemos que, si bien parece acertada la necesidad de extender el límite objetivo de la misma más allá del estricto tenor del fallo, es posible que de nuevo en este aspecto su excesiva atención a la "prohibición de repetición" del acto, le lleve a una solución, la "concreta norma de decisión", que en la concreta definición de Vogel parece aún intentar cumplir con algunas de las funciones del concepto de "Bindungswirkung". Se descartan así otras soluciones conceptuales que atienden en mayor medida a la cuestión básica del "significado" de la disposición enjuiciada en relación con el sistema normativo y con su evolución, y por tanto a la identidad real entre "res iudicata" y "res iudicanda" 63.

La conceptualización de los límites subjetivos de la cosa juzgada adolece a nuestro juicio de mayores indefiniciones. Por una parte, en la sentencia estimatoria, la continua alusión a los efectos generales parece aludir, dado el hilo lógico del discurso, a una cosa juzgada privada de límites subjetivos, o lo que es lo mismo, dotada de límites subjetivos "erga omnes". Tal identificación entre efectos generales y límites subjetivos "erga omnes" de la cosa juzgada no sólo puede llevar a oscurecer el significado de la previsión constitucional de estos efectos generales, en cuanto referidos a la vertiente jurídico-material de la sentencia, sino que tampoco es estrictamente necesaria. Detrás de la postura de Bocanegra subyace la concepción mayoritaria, pero no unánime, sobre la falta de limitación subjetiva de la cosa juzgada en las sentencias constitutivas de anulación ${ }^{64}$. No obstante, una separación entre efectos jurídico-materiales de anulación, y por tanto "erga omnes" si se trata de una norma general, y límites subjetivos de la cosa juzgada "inter partes" en dicho pronunciamiento, puede resultar de utilidad a la hora de abordar por ejemplo el problema de la

63. Nos referimos por ejemplo al concepto de "situación normativa" como objeto de la cosa juzgada constitucional, acogido por un sector de la doctrina italiana. Entendiendo que toda sentencia del TC refleja " una valoración comprensiva de las interconexiones posibles entre el entero ordenamiento y la norma impugnada", la Corte debe buscar "Una situación normativa mayormente conforme (o menos disconforme) con respecto a los valores constitucionales, viendo sus posibles efectos y sus consecuencias temporales sobre la relatividad del entero ordenamiento", vid Ruggieri, Storia di.un "falso...op. cit., p. 116 y ss. Vid también Giannini, ya en 1956, "Alcuni caratteri della giurisdizione di legitimità delle norme" en Giur. Cost., o Spadaro "Contributo per una redifinizione della teoria della validità" en La giurisdizione costituzionale a una svolta, op cit , y la amplia bibliografía alli citada. Con este concepto flexible del objeto de la sentencia se permite la posibilidad de evolución a través del cambio, bien de la norma, bien del ordenamiento, bien incluso de la relación norma/ordenamiento. Mientras la "situación normativa" permanezca idéntica, permanecerá la fuerza de cosa juzgada del pronunciamiento constitucional, siendo en último término el propio Tribunal Constitucional quien deberá decidir sobre la subsistencia de la identidad.

64. Vid, para la jurisdicción contencioso- administrativa, la exposición del problema en Perez Andrés, Los efectos de las sentencias de la jurisdicción contencioso-administrativa. Pamplona 2000, especialmente las posturas de autores como Cortes Domínguez o Cordón Moreno 
cosa juzgada en las sentencias estimatorias que no contemplen la nulidad de la norma.

Es sin embargo en el campo de la sentencia desestimatoria donde los límites subjetivos del efecto de cosa juzgada trazados por el autor se vuelven indicativos de una cierta indefinición de fondo sobre el concepto de "juicio constitucional’. Así se afirma que no sólo el resto de los ciudadanos, sino el propio juez que elevó la cuestión de inconstitucionalidad podría, si las partes del juicio "a quo" son distintas, elevar de nuevo la cuestión, aunque "otra cosa es, como también se ha anotado, que el Tribunal Constitucional puede no admitirlas a trámite por notoriamente infundadas (art. 37. LOTC),65. En definitiva el Alto Tribunal podrá admitir o no la cuestión, pero no se encontrará sujeto a la obligación jurídica de rechazar la misma por existir una excepción de cosa juzgada.

Con ello se llega al aspecto central del planteamiento estudiado. Dado que la posibilidad de revisión jurisprudencial ocurrirá en la práctica por el planteamiento de cuestiones sucesivas a un recurso o a una primera cuestión, la delimitación subjetiva del efecto de cosa juzgada a las partes del juicio "a quo" en la cuestión permite el replanteamiento de la duda constitucional. Pero con ello será suficiente un mero cambio en la identidad de los legitimados en un concreto juicio ordinario para deshacer la identidad subjetiva de la cosa juzgada constitucional y anular así su eficacia, aun cuando permanezca la identidad objetiva entre "res iudicata" y "res iudicanda". Se daría entonces la extraña circunstancia de que, planteada una nueva cuestión de inconstitucionalidad sobre una duda idéntica, ésta sea aceptada por el Tribunal Constitucional, que no está obligada a rechazarla al no existir la identidad subjetiva, y se abra un trámite de alegaciones donde las "partes" de este juicio "ad quem" sean exactamente idénticas a las "partes" del primer juicio que terminó con un pronunciamiento desestimatorio del recurso, o de la primera cuestión. La mera elevación de la cuestión de inconstitucionalidad por alguien que indudablemente no es parte del juicio "ad quem", puede provocar según esta teoría una repetición del juicio, donde el límite objetivo y las partes procesales, que deben constituir en buena lógica el límite subjetivo, sean exactamente idénticas. Y todo ello por la identificación entre juicio "ad quem" y juicio "ad quo", entre "juicio constitucional" y posibilidad de elevar la duda de inconstitucionalidad.

En el fondo, parece necesitarse una teoría de la cosa juzgada que por una parte haga posible evitar la repetición de juicios idénticos, y que por otra no impida que lleguen al Tribunal dudas de inconstitucionalidad que permitan al propio órgano decidir cuándo se encuentra ante un nuevo problema constitucional. Y todo ello haciendo compatible el efecto de cosa juzgada con el efecto de vinculación a los poderes públicos, entre ellos a la magistratura, que

65. Op. cit., p. 277. 
establece, conjuntamente con el de cosa juzgada, el art 38.1 de la LOTC. La propuesta aquí estudiada demostró en su momento su eficacia para salvar conceptualmente la compatibilidad entre el recurso de y la cuestión de inconstitucionalidad, permitiendo así el necesario dinamismo en el ordenamiento. Pero es esta misma exigencia de dinamismo la que, como vimos, preservó hace tiempo el Tribunal Constitucional con su jurisprudencia, al optar por la compatibilidad entre las dos vías de acceso en base a una interpretación literal y aislada del art. 38.1 de la LOTC. Por ello mismo, y en una más de las paradojas de la dogmática del artículo 164 de la Constitución, hoy ya no es necesario elaborar una teoría de la cosa juzgada para hacer compatibles recurso y cuestión, sino, por el contrario, encontrar una teoría de la cosa juzgada que no resulte contradictoria con esa misma compatibilidad.

\section{LA NEGACIÓN DE LOS LÍMITES SUBJETIVOS DE LA COSA JUZGADA EN LA SENTENCIA CONSTITUCIONAL SOBRE LA LEY: LA COSA JUZGADA “ERGA OMNES" TAMBIÉN PARA LA SENTENCIA DESESTIMATORIA}

La consagración en el artículo $164 \mathrm{CE}$ de un efecto de cosa juzgada para las sentencias del Tribunal Constitucional, junto con la indicación de que " las que declaren la inconstitucionalidad de una ley o de una norma con fuerza de ley y todas las que no se limiten a la estimación subjetiva de un derecho, tienen plenos efectos frente a todos", a lo que hay que añadir la mención, conjunta y sin más precisiones, a los efectos generales y a la cosa juzgada del art. 38.1 LOTC, suponían una cierta base normativa para una interpretación de los efectos generales de las sentencias constitucionales que tendiera a identificar tales efectos con una ausencia de límites subjetivos del uiudicato" constitucional.

Dejando aparte los problemas que puede suscitar tal asimilación en las sentencias estimatorias, nos referiremos aquí a una corriente doctrinal, si bien no mayoritaria, que tiende a identificar efectos generales y cosa juzgada "erga omnes" también en los pronunciamientos que rechazan la inconstitucionalidad de la ley.

Semejante opinión no carecería de relevancia aunque sólo fuera por haber sido sostenida por los dos primeros procesalistas españoles que estudiaron con detenimiento el nuevo sistema de jurisdicción constitucional ${ }^{66}$. Su interés se acrecienta, sin embargo, en cuanto recientemente, y en parte recogiendo una sugerencia ya apuntada por Elizalde ${ }^{67}$, ha sido brillantemente mantenida por Garrorena en su aportación al comentario sistemático de la Constitución

66. Gonzalez Perez, Derecho Procesal Constitucional. Madrid 1980, y Almagro Nosete, Justicia Constitucional. Valencia 1981 ( y 1992).

67. Pedro Elizalde y Aymerich, "El Tribunal Constitucional y la jurisprudencia", en EL Tribunal Constitucional I, Madrid 1981, pg 861 y ss. 
dirigido por Oscar Alzaga ${ }^{68}$. La precisión que realiza Garrorena acerca de la existencia de un nuevo límite, el de la vía de acceso, para la prohibición de replantear la duda constitucional, y su distinto enfoque general, aconsejan sin embargo un tratamiento diferenciado de ambas posturas.

Es González Pérez el primer autor español que mantiene la existencia de una cosa juzgada sin límites subjetivos para la sentencia desestimatoria del control de leyes. Tras un análisis exquisitamente procesal del resto de los efectos de la sentencia, la "res iudicata" queda encuadrada como el efecto jurídico-procesal por antonomasia del pronunciamiento del Tribunal. Con ello, a nuestro juicio, el autor ayuda a precisar la naturaleza jurídico-material de los "efectos frente a todos" previstos en el art. 164 C., y en el fondo, a diferenciar el problema de la eficacia de la anulación del de la determinación del ámbito subjetivo de la cosa juzgada ${ }^{69}$. La diferencia entre ambas, sin embargo, se plasma en su Derecho procesal constitucional a un nivel meramente expositivo, en cuanto, en su análisis de la cosa juzgada, inmediatamente relaciona el art. $164 \mathrm{CE}$ con la extensión de la institución. Así mantiene que "Dada la amplitud de efectos que se reconocen a la sentencia en el proceso constitucional (art. 164), aquel principio procesal (la vinculación a las partes de la cosa juzgada) sólo se aplicará a los supuestos en que la sentencia se limite a la estimación subjetiva de un derecho, en todos los demás supuestos, la sentencia del Tribunal Constitucional, sea estimatoria o desestimatoria, producirá efectos (jurídico-materiales y jurídico-procesales) erga omnes ${ }^{70}$.

Parece pues que detrás de la concepción del estudioso del proceso contencioso-administrativo subsiste aún la correlación entre sentencia constitutiva de anulación y desaparición de los límites sujetivos de la cosa juzgada ${ }^{71}$. La "res iudicata" queda además rigurosamente reducida al "fallo", y el replanteamiento de la duda constitucional en manos de la variación del límite objetivo, "ante la imposibilidad de replantear que se dará respecto a cualquier sujeto" ${ }^{72}$.

Más elaborada sin duda es la construcción de. Almagro Nosete sobre el art. 38 LOTC, quien no deja de señalar que si «en principio todas las sentencias tienen efectos generales", "no obstante ni la materialidad de los efectos, ni las limitaciones que impone la cosa juzgada dejan de ofrecer importantes matices que, apuntados en la LOTC, dependen de una riqueza de soluciones concretas del Tribunal Constitucional, ${ }^{73}$. Para Almagro es el objeto del proceso el que determina un efecto general que hará desaparecer los límites subjetivos de la

68. "Artículo 164" op cit. No cabe olvidar que es este mismo constitucionalista el autor de una de las más prontas aportaciones al estudio de la sentencia constitucional tras la promulgación de la LOTC; vid. "La sentencia constitucional", op cit.

69. Derecho procesal Constitucional, op. cit., p. 165.

70. Op. cit., p. 169.

71: Sobre la postura de González Pérez sobre este tema en concreto, vid sus Comentarios a la Ley de Jurisdicción Contencioso-administrativa, Madrid. 1998, pg 1208 y ss.

72. Op. cit., p. 170

73. Justicia Constitucional op. cit., p. 113. 
cosa juzgada, pero no los objetivos ( concretados en la motivación específica de la duda). De ahí que las sentencias desestimatorias" "produzcan efectos generales en los límites de la desestimación, y no impidan el planteamiento de la inconstitucionalidad de la misma norma legal por motivos diferentes ${ }^{75}$.

Parece evidente que en ambos autores la desaparición de los límites subjetivos de la cosa juzgada obliga a centrar en los límites objetivos la posible evolución de la jurisprudencia constitucional. Y es Almagro el más consciente de esta necesidad, hasta tal punto que sostendrá que, en definitiva, "los efectos generales de la desestimación pueden quedar muy difuminados en relación con la identidad del objeto" ${ }^{76}$. Al procesalista no se le oculta que la desestimación se basa en una interpretación de las normas legales, o constitucionales añadiríamos, y que como tal, con el paso del tiempo puede cambiar, determinando una transformación en lo que denomina "estado de hecho". Claramente afirmará que entonces " ya no nos encontramos ante la misma cuestión "77.

Tema distinto es la relación de todo ello con la postura mantenida por estos autores en torno a la compatibilidad entre recuso y cuestión de inconstitucionalidad. Para Almagro es evidente que, manteniendo la identidad del objeto, " admitir un nuevo planteamiento de la misma cuestión (duda de inconstitucionalidad), aunque fuera en otra vía, equivale a desconocer el efecto general de todas las sentencias reconocido en el art. 38.1 de la LOTC ${ }^{78}$. Semejante planteamiento, que corroborará en el fondo el sostenido por quienes entienden, a "sensu contrario", que una imposibilidad de plantear la CI tras el RI supone una extensión de la cosa juzgada "erga omnes", para ellos inadmisible, no es estrictamente necesario, y buena prueba de ello serán las aportaciones al debate de Elizalde o Garrorena. Los dos harán compatibles ambos supuestos: cosa juzgada "erga omnes" y autorización de una cuestión de inconstitucionalidad tras la sentencia desestimatoria de un recurso directo.

La postura de Elizalde, recogida en su trabajo «El Tribunal Constitucional y la jurisprudencia ${ }^{79}$, merece destacarse por ser toda una muestra del escrupuloso respeto del jurista a unas prescripciones normativas que no comparte, pero en las que debe bases a la hora de elaborar una teoría de los efectos acorde con la regulación del sistema.

74. Obviamente una sentencia desestimatoria de fondo. Para la desestimación por motivos formales el autor reconoce un efecto de cosa juzgada, si bien limitado a impedir un nuevo proceso en donde se repitan las causas obstativas de naturaleza procesal. En todo caso, y por este mismo concepto de cosa juzgada para la desestimación "formal", Almagro no deja de reconocer que en este supuesto "no puede decirse con propiedad que el pronunciamiento produzca efectos generales", op. cit., p. 110.

75. Op. cit., p. 113.

76. Op.cit., p. 115.

77. Op. cit., p. 115.

78. . Op. cit., p. 98.

79. Op. cit., pp. 861 y ss. 
Parte Elizalde de la interpretación del art. 38.1 de la LOTC para llegar a la conclusión de que en dicha norma se atribuyen efectos generales tanto a la sentencia estimatoria como a la desestimatoria, en cuanto no es posible establecer entre ambos tipos una distinción que el texto legal no realiza ${ }^{80}$. Ello no es óbice para que el autor considere que semejante atribución "incurre así en un evidente exceso respecto a la Constitución, que sólo atribuye efectos generales a ulas sentencias que declaren la inconstitucionalidad de una ley" ${ }^{81}$. Su posición de fondo sobre el tema es pues muy clara, sólo las sentencias estimatorias deberían gozar de efectos generales "en cuanto sólo ellas innovan el ordenamiento", las sentencias de rechazo carecen de efecto innovador "e incluso la debida defensa de la Constitución exigía negarles tales efectos generales $" 82$.

La peculiaridad del planteamiento de Elizalde consistirá en utilizar la interpretación de la LOTC, y aquí curiosamente del art. 38.2, con una finalidad clara: "permitir reducir el exceso (del art. 38.1), aun cuando no sea posible corregirlo totalmente" 83 . De ahí que el autor se vea "forzado" a admitir que la sentencia desestimatoria del recurso de inconstitucionalidad tendrá un efecto de cosa juzgada sin imposición de límite subjetivo alguno, para inmediatamente, y basándose en la prescripción del art.38.2 interpretada en su sentido implícito, mantener la existencia de dos límites "especiales" para este efecto: uno objetivo, el de no volver sobre idéntico precepto constitucional, otro procesal, el de no utilizar la "misma vía". Si asimilamos, aunque no sea exacto, el primer límite al mantenimiento de la identidad objetiva entre "res iudicata" $y$ "res iudicanda", es obvio que, junto al límite subjetivo inamovible, la variación en el objeto permitirá una desaparición de la sujeción, en la línea de los procesalistas analizados anteriormente ${ }^{84}$. La novedad se centra pues en ese nuevo "límite procesal" utilizado por Elizalde para reducir aún más los efectos de un cosa juzgada que entiende a la vez general y excesiva. La consideración del establecimiento de una compatibilidad entre recurso y cuestión de inconstitucionalidad como un "límite procesal" de la institución de la cosa juzgada no deja de plantear sin embargo dificultades conceptuales independientemente de la finalidad que aquí en concreto asuma. No parece que sea aceptable configurar "ad hoc" límites nuevos a una institución de dogmática ya muy consolidada, y la prescripción de compatibilidad entre los dos procedimientos puede entenderse, como veremos que hace Garrorena, no tanto como un límite "intrínseco" de la cosa juzgada, cuanto como un elemento normativo y por

80. Op. cit., p.

81. Op. cit., p.

82. Op. cit., p. 877. Hay pues en todo el planteamiento una cierta indefinición entre el efecto jurídico-material de la anulación y el efecto jurídico-procesal de la cosa juzgada.

83. Op. cit., p.

84. Aunque no debe olvidarse que en caso de Elizalde, tan sólo referido a la sentencia desestimatoria del recurso de inconstitucionalidad. 
tanto "ad extra" que incide en la configuración de sus concretos efectos en un determinado procedimiento ${ }^{85}$.

Por último, es necesario precisar que Elizalde tan sólo reconoce este efecto "erga omnes" de la cosa juzgada, si bien con los dos límites señalados, para la sentencia desestimatoria del recurso de inconstitucionalidad. De manera no del todo coherente con su planteamiento inicial, en la sentencia desestimatoria de la cuestión de inconstitucionalidad, el autor observa que falta una regulación de sus efectoș ${ }^{86}$. Olvidándose aquí de la atribución conjunta de efectos generales que en su propia opinión realiza el art. 38.1 LOTC, mantendrá que en este caso es amejor prescindir del art 38 LOTC e ir directamente al artículo 164 de la Constitución, ${ }^{87}$. De tal manera que se produciría una falta de armonía entre los efectos del pronunciamiento desestimatorio según éste lo sea del recurso o de la cuestión. Si el primero goza de una eficacia "erga omnes", para el segundo, la sentencia desestimatoria de la cuestión de inconstitucionalidad, el efecto de cosa juzgada se limitará " al juez y a las partes de ese proceso" ${ }^{88}$, logrando así una reproponibilidad de cuestiones sucesivas indispensable para salvar el dinamismo de la jurisprudencia constitucional, gravemente amenazado por la dicción literal del art. 38.1 de la LOTC.

Sin embargo, la atribución de fuerza "erga omnes" a las sentencias desestimatorias en general no hubiera pasado seguramente de un pequeño apunte doctrinal, producto para algunos de una visión excesivamente procesalista de la nueva jurisdicción, y fruto de la inmediatez con que se procedía a su análisis para otros, si no hubiera sido reafirmada muy recientemente por Garrorena en su contribución a los Comentarios a la Constitución española de $1978^{89}$ dirigidos por Alzaga. El catedrático de Murcia, que sostiene tan sólo recoger "de la manera más esclarecedora posible el estado de la cuestión" „90, realiza sin embargo un lúcido estudio de los efectos de todas las sentencias del Tribunal Constitucional, donde se manifiesta una clara voluntad de "problematización" de la dogmática sobre el art. $164 \mathrm{C}$, una dogmática que casi veinte años después aún se juzga "insuficiente ${ }^{91}$.

Dejando aparte aquí el resto de sus reflexiones sobre los efectos de los pronunciamientos, nos centraremos en este momento en su delimitación de la

85. De acuerdo en todo caso con la concepción "no sustancial" de la institución de la cosa juzgada sostenida mayoritariamente por la doctrina procesalista. Por todos, Guasp, Derecho Procesal civil (adap Aragoneses), Madrid. 1988, pg 516 y ss, de la Oliva Sobre la cosa juzgada, op. cit., p. 34 y ss. o Pugliese, voz "Giudicato civile (diritto vigente)", en Enciclopedia del Diritto, Milano, pg 836-846.

86. En línea con una interpretación literal de los art. 28.2 y 38.2 de la LTOC que, como vimos, tan sólo aluden a la desestimación por razones de forma y por razones de fondo del RI respectivamente.

87. Op. cit., p. 878.

88. Op. cit., p. 879.

89. "Artículo 164", op. cit.

90. Op. cit., p. 335.

91. Op. cit., p. 333. 
cosa juzgada en las sentencias desestimatorias. Para ello creemos necesario exponer, al igual que hicimos con la teoría de Bocanegra, las líneas maestras de su contribución, en cuanto junto con la del autor citado, probablemente constituyan las dos reflexiones más importantes sobre la figura del "giudicato" constitucional.

Garrorena atribuye a la cosa juzgada en general la finalidad de impedir la reiteración o sucesión de procesos idénticos, coincidiendo pues con Bocanegra en resaltar el aspecto "obstativo" de la institución frente al llamado efecto positivo prejudicial.

Parte también el autor de una afirmación general: para todo tipo de procesos constitucionales es posible afirmar el valor de cosa juzgada. No sólo porque así lo recoja el art. $164 \mathrm{CE}$, sino porque la finalidad de la institución también tiene sentido dentro de la jurisdicción constitucional ${ }^{92}$. Sin embargo, y en esto discrepa de Bocanegra, no cree posible una teoría de la cosa juzgada que obvie las peculiaridades de tal institución en cada proceso constitucional. Será precisamente en el control de constitucionalidad de las normas con rango de ley donde Garrorena aprecie que se produce unna modificación bastante profunda de las condiciones que definen en Derecho Procesal común a la cosa juzgada material, 93 .

En cuanto a los pronunciamientos desestimatorios en el control de leyes, éstos estarán dotadas también de un efecto de cosa juzgada cuya justificación resulta aquí más evidente: "la reiteración de procesos por el juez de la constitucionalidad debe tener un freno, y ese freno, en puro respeto a las categorías ya acuñadas, no puede ser otro que la cosa juzgada material ${ }^{94}$.

Una de las mayores novedades del razonamiento de Garrorena se encontrará en su afirmación de la inexistencia de límites subjetivos para la cosa juzgada en este tipo de pronunciamientos. Difiere así su postura de la mantenida por la mayoría de la doctrina, quien con diversas argumentaciones cuestiona como vimos, ya no sólo los límites subjetivos de la institución en la sentencia desestimatoria sino incluso en ocasiones su propia existencia. La audacia doctrinal es mayor en cuanto las críticas más fuertes se han dirigido siempre contra esta supuesta extensión, que al hilo de su relación con la imposibilidad de reproponer la "duda constitucional ${ }^{95}$, se ha tachado muy frecuentemente en la doctrina española, y en la italiana, de antitética con los postulados básicos de la jurisdicción constitucional, no encontrando por otra parte mayor apoyo en la literatura jurídica nacional que los ya lejanos artículos ante-

92. Op. cit., p. 338 .

93. Op. cit., p. 342. Para empezar en las sentencias estimatorias, donde el autor, aún afirmando su existencia, considera innecesaria su aplicación dado el efecto jurídico-material de la declaración de inconstitucionalidad, al margen del posible funcionamiento de la cosa juzgada en las escasísimas sentencias interpretativas del Tribunal que adoptan forma estimatoria.

94. Op. cit, p. 344. LOTC.

95. Y generalmente por tanto en relación con la interpretación de los art. 28.2 y 38.2 de la 
riormente señalados.

Para este autor, en cambio, la extensión subjetiva se deriva directamente de la generalidad de los destinatarios de la sentencia, y sólo de manera indirecta del carácter general de la norma enjuiciada ${ }^{96}$. La cosa juzgada, por tanto, impedirá la repetición de procesos idénticos "cualquiera que sea el supuesto (demandante o juez "a quo") que los inste" "97. Con ello, no hace falta decirlo, y en clara oposición a Bocanegra, Garrorena renuncia al juego de los límites subjetivos a la hora de garantizar la evolución de la jurisprudencia constitucional.

La eliminación de tales límites le lleva a entender que la sentencia desestimatoria producirá un efecto vinculante/obstativo respecto del juez "a quo", por su innegable eficacia prejudicial, respecto de los demás jueces, "los cuales deberán considerar impedido para el futuro el planteamiento ante el Tribunal Constitucional de cuestiones idénticas", salvo que las apoyen "en la concreta causa de la modificación del sentido y alcance de la norma utilizada como parámetro" 98 , y también, y no por ello menos importante, frente al propio TC "al que se veda admitir en la misma vía solicitudes de procesos ya zanjados por él "salvo que se da la misma circunstancia que se señaló para la magistratura" 99 .

Las rigurosas consecuencias de tal extensión de la cosa juzgada vendrán sin embargo amortiguadas por la existencia de dos excepciones al régimen general de la institución. Para Garrorena, una primera "retracción lógica del instituto" 100 se producirá debido a la expresa regulación legal del régimen de relaciones entre la cuestión y el recurso de inconstitucionalidad. El autor realiza una interpretación "clásica" del juego de los art. 28.2 y 38.2 de la LOTC para llegar a la conclusión de que el sistema de impugnación se basa en una compatibilidad sustancial entre recurso y cuestión de inconstitucionalidad. Compatibilidad que encuentra por otra parte su razón de ser constitucional en la finalidad propia de la cuestión de inconstitucionalidad: convertirse en una vía abierta a las exigencias que se derivan de la aplicación concreta del derecho' ${ }^{101}$.

Semejante interpretación no convierte en incompatible a la cosa juzgada con la regulación de la LOTC, sino que simplemente modifica por vía norma-

96. Op. cit., pp. 344-45.

97. Op. cit., p. 345.

98. Op. cit., p. 347 y 350.

99. Op. cit., p. 347. La reafirmación de la obligación jurídica que para el propio Tribunal supone el efecto de cosa juzgada es muy clara y expresa, así vid. pg. 345, donde se mantiene que el TC no sólo no debe, sino que no puede admitir dudas constitucionales idénticas.

100. Op. cit., p. 346.

101. Op., cit. p. 346. Cabe señalar que se subraya más en el comentario la polaridad concreto/abstracto de la cuestión de la $\mathrm{CI} / \mathrm{CI}$ que el hecho de que la cuestión de inconstitucionalidad, en palabras de Jiménez Campo, "Consideraciones sobre el control de las leyes en el derecho español, op cit., p. 82, sea el camino para lograr "el principio de reversibilidad de los pronunciamientos constitucionales". 
tiva el régimen general del instituto. No existe sin embargo ningún precepto legal que justifique la exclusión de la cosa juzgada en los casos de repetición de acceso por la misma vía, y por tanto en estos supuestos (recurso más recurso de inconstitucionalidad y cuestión más cuestión de inconstitucionalidad) el planteamiento de una idéntica duda constitucional ${ }^{102}$, dada la ausencia de límites subjetivos de la CJ, implicaría la imposibilidad para el Tribunal Constitucional de entrar a conocer el fondo del asunto ${ }^{103}$. El reconocimiento de una limitación por vía legal al normal efecto de la cosa juzgada permite así al autor garantizar el dinamismo del sistema sin renunciar a la eliminación de los límites subjetivos del "iudicato" 104 .

Otra de las aportaciones de Garrorena al debate doctrinal sobre los efectos de las sentencias será sin duda su consideración de la "no vinculación del Tribunal Constitucional a sus precedentes" como un principio que entrará en juego necesariamente a la hora de garantizar la evolución jurisprudencial. Tal principio, cuya lógica "corresponde al principio de reversibilidad de los precedentes judiciales, o lo que es igual.... de la jurisprudencia " ${ }^{105}$, es rigurosamente delimitado por el autor en relación al concepto de cosa juzgada ${ }^{106}$. Si la cosa juzgada obedecía a la finalidad de evitar la repetición de procesos idénticos, el principio de no vinculación tenderá a impedir la petrificación de la jurisprudencia. De ahí que sus propios objetos sean distintos, "la cosa juzgada material versa efectivamente sobre la norma ordinaria objeto del recurso, de la cual se afirma que ha revisado ya con firmeza su compatibilidad con la Constitución. La decisión del Tribunal que reconsidera su propia jurisprudencia recae, en cambio, sobre la regla constitucional, esto es, sobre la regla de derecho utilizada para resolver tal recurso" ${ }^{107}$.

Por lo tanto, la actuación del principio de reversibilidad, o no vinculación, es un indicio claro de que la norma-parámetro se ha transformado, y por ello de que es posible abrir un nuevo proceso. En definitiva, el principio expresa la posibilidad de un cambio de parámetro que disuelve la identidad objetiva entre "res iudicata" y "res iudicanda", o, como expresivamente señala el autor, el proceso se celebra "porque este proceso.... no se ha celebrado nunca antes de ahora " ${ }^{108}$. Es esta vía de cambio la que permitiría la admisión de una tras una sentencia desestimatoria de otra cuestión de inconstitucionalidad anterior

102. Es decir, siempre que "sea el mismo el precepto impugnado e igual la causa o fundamento en que tal impugnación se base", op. cit., p.

103. Op. cit., p. 347.

104. Obsérvese que, a diferencia de Elizalde, Garrorena no considera tal limitación un límite "intrínseco" de la cosa juzgada, circunscribiendo por otra parte a la diferencia de vías la posibilidad de plantear "dudas" ya resueltas.

105. Op. cit., p. 348.

106. En su construcción no puede dejar de percibirse un cierto tono defensivo frente a quienes utilizan tal principio como un argumento más para rechazar la posibilidad de un efecto de cosa juzgada en las sentencias constitucionales.

107. Op. cit., p. 349.

108. Op. cit., p. 349. 
sobre la misma norma (o bien de dos improbables recursos de inconstitucionalidad sucesivos) sin por ello significar que no rija para estos supuestos el efecto de cosa juzgada. Por este camino por tanto el juez ordinario puede volver a elevar la cuestión de inconstitucionalidad y el Tribunal Constitucional podría admitirla a trámite ${ }^{109}$.

Es indudable que, desde una perspectiva crítica, el trabajo de Garrorena contribuye a "desbrozar" el ya amplio y confuso panorama doctrinal sobre el efecto de cosa juzgada en las sentencias constitucionales. Encontramos en primer lugar una seria reafirmación de la validez del concepto para describir la eficacia de los pronunciamientos. Una postura que adquiere todo su significado en un momento en que empiezan a predominar las voces que cuestionan la existencia de la cosa juzgada en el proceso constitucional. La referencia a la necesidad de tener en cuenta un ordenamiento que por dos veces, y una a nivel constitucional, consagra expresamente la figura, se enlaza sólidamente con la consideración de la idoneidad de su finalidad, la prohibición de repetición de procesos idénticos, en el marco de la jurisdicción constitucional.

No es tampoco menor el esfuerzo por delimitar la figura y sus específicos efectos en cada tipo de proceso constitucional. Dos décadas de jurisprudencia constitucional no pasan en balde y los rasgos propios, tanto de cada proceso, como del efecto de inmutabilidad producido en cada uno, aconsejan desistir de intentos globalizadores como los de Bocanegra.

Dentro de esta perspectiva general consideramos también especialmente útil la reafirmación de la vinculación, que, como efecto propio de la cosa juzgada, afecta también al propio Tribunal Constitucional. No es bueno que para la doctrina constitucional pasara desapercibida toda una corriente teórica procesal que precisamente sitúa como primer sujeto vinculado por el efecto de cosa juzgada al propio tribunal que ha de juzgar o que juzgó ${ }^{110}$. Es en este contexto en el que encuentran plena justificación las continuas referencias de Garrorena al carácter "no potestativo" del conocimiento de la causa por el Alto Tribunal. Coincidimos pues con él en que si el efecto de cosa juzgada se da, y no olvidemos que en este supuesto el TC es Tribunal único y permanentemente afectado, el órgano no puede jurídicamente entrar a conocer ${ }^{111}$.

Muy importante también en el planteamiento del autor resulta su acentuación de la movilidad del parámetro constitucional y lo que ello implica a

109. Para Garrorena esto supone que si bien el efecto de cosa juzgada material nunca deja de producirse en los procesos de control de constitucionalidad como "excepción" que oponer a otros procesos, puede en cambio cesar como "mandato" público que vincula al TC, esto sí, únicamente cuando el principio de reversibilidad de su jurisprudencia lo autorice.

110. De hecho esta es la base conceptual de toda la teoría procesal de la cosa juzgada, desde Helwig, en su Wesen und Subjetive Begrenzung des Rechtkraft, en adelante.

111. Cuestión distinta es la posibilidad de exigir jurídicamente, o al menos de controlar, semejante obligación del juez constitucional. No es mal camino sin embargo empezar reconociendo doctrinalmente tal obligación jurídica. 
la hora de determinar la identidad entre la "res iudicata" y la "res iudicanda", pero ante todo, su clara intuición de la simplificación que a veces se encierra en el axioma del cambio de parámetro constitucional como elemento "objetivo" y "externo" que determina la no producción de la cosa juzgada y por ende la posibilidad para el TC de entrar a conocer. Si no hemos comprendido mal el planteamiento del autor, parte de la finalidad de su concepción de la "no vinculación al precedente" consiste en intentar enmarcar constitucionalmente, y en términos más o menos jurídicos, la innegable capacidad del Tribunal para modificar el propio parámetro. En efecto; es difícil no reconocer que la existencia de una obligación jurídica para el TC en base al efecto de cosa juzgada, y su capacidad simultánea para en cierto modo alterar él mismo el parámetro constitucional, y por lo tanto el límite objetivo y, al fin, la propia existencia de ese efecto al que se le dice vinculado, relativiza cualquier construcción doctrinal sobre la efectividad de la vinculación del instituto.

Desde el plano de la determinación específica de los límites de la cosa juzgada guardamos sin embargo algunas divergencias con el trabajo del autor. Parece ya hoy evidentemente que los art. 28.2 y 38.2 de la LOTC consagran, si bien por vía de interpretación jurisprudencia y doctrinal, un sistema de compatibilidad entre el recurso y la cuestión de inconstitucionalidad. Ahora bien, no parece del todo exacto entender esta compatibilidad como una "retracción" de la cosa juzgada para el caso. O al menos semejante conclusión necesita una demostración, que al no ser una consecuencia necesaria, deberá ser forzosamente jurisprudencial. Pensamos que en principio es lógicamente posible que se permita una cuestión de inconstitucionalidad tras un recurso de inconstitucionalidad y que a la vez subsista una posible cosa juzgada que, como siempre, deberá apreciar el Alto Tribunal. Pero esta "doble compatibilidad" entre la cosa juzgada y la regulación legal y entre recurso y cuestión de inconstitucionalidad, tiene que partir de un concepto de cosa juzgada que lo permita. La aceptación de una supuesta eficacia "erga omnes" del "giudicato" implica lógicamente que, consolidada la fórmula de la posibilidad del recurso y la cuestión sucesiva, ésta deba necesariamente configurarse como regla legal que excluye la cosa juzgada en este supuesto. Pero tal excepción al general principio del art. $164 \mathrm{C}$ y del 38.1 LOTC debe asumirse conscientemente como consecuencia directa de una concepción "erga omnes" de la cosa juzgada. Dado que de la jurisprudencia del TC no parece posible extraer una aceptación expresa del conocimiento de "dudas constitucionales" iguales, vía cuestión de inconstitucionalidad tras el recurso de inconstitucionalidad, puede resultar más adecuado a la regulación constitucional, una determinación subjetiva del instituto que permita su subsistencia aún dentro del marco de la compatibilidad entre recurso y cuestión.

Por otra parte no puede olvidarse que la existencia de una cosa juzgada "erga omnes" no deja de resultar una excepción al régimen general de la 
figura $^{112}$, de tal forma que la configuración de una sentencia desestimatoria con semejante ámbito subjetivo parecería escapar a ese "mínimo respeto al derecho procesal" que el derecho procesal constitucional debe guardar. Es cierto que gran número de las críticas a la figura se basan en la "petrificación" que tal efecto implicaría para la jurisprudencia constitucional. Este inconveniente es suficientemente salvado en la teoría del autor a través de la previsión legal de compatibilidad entre recurso de inconstitucionalidad/cuestión de inconstitucionalidad y el principio de no vinculación del Tribunal a sus propios precedentes. Pero queda por demostrar la razón de la excepcionalidad de un efecto que no encuentra más apoyo que la ambigua regulación normativa (art. 164 C y 38.1 LOTC), y la justificación en la "generalidad" de los destinatarios de la decisión. Sobre la primera cuestión no parece necesitarse hacer mayor hincapié dado su carácter justificativo de cualquier opción doctrinal que se elija y su permanente indefinición por parte del Tribunal Constitucional ${ }^{113}$.

Más difícil resultan de comprender las razones por las cuales la generalidad de los destinatarios, reflejo de la eficacia general de una norma que, recordemos, no se ha anulado, justificaría una extensión "erga omnes" de la cosa juzgada. La sólida tradición del contencioso-administrativo parece recordar permanentemente la dicotomía entre efectos generales de la anulación y eficacia "inter partes" de la sentencia desestimatoria. Es cierto que el principio subyacente bajo tal planteamiento es la protección del derecho de defensa del extraño al juicio de anulación, en último término del art. 24. CE, y que tal justificación es improcedente en el proceso constitucional. Pero en todo caso, invirtiendo los términos, deberíamos encontrar un principio justificativo más sólido a la excepción a un régimen casi "consustancial" al instituto. Semejante justificación tan sólo podría proceder de una genérica utilidad de la extensión en relación con los fines propios de la cosa juzgada, la prohibición de repetición, y estar en consonancia con las especiales características del control de leyes. No resulta fácil sin embargo encontrar esa utilidad.

En primer lugar la extensión se concretaría, cuando no se justificaría, en la vinculación del Tribunal Constitucional a su propia decisión. Semejante vinculación creemos que es más bien una consecuencia del propio concepto de cosa juzgada y del carácter de jurisdicción única que ostenta el Tribunal, y, en último término, supone la concretización del funcionamiento real del instituto, por lo que el objetivo se conseguiría con sólo aceptar el efecto de cosa juzgada, sean cuales sean los límites subjetivos que se le quieran reconocer.

Por otra parte, la extensión afectaría al juez del proceso "a quo", vinculación que se conceptúe como preclusión o como cosa juzgada, resulta casi imposible dejar de reconocer dado el tenor literal del art. 38.3 LOTC.

112. Negada incluso, como vimos, a la sentencia estimatoria por un sector doctrinal, que distingue en la sentencia constitutiva de anulación entre efectos generales jurídico-materiales y efectos jurídico-procesales reducidos a las partes.

113. Eludiendo éste una tarea que quizás correctamente entienda que no le corresponde. 
Más problemática resulta la vinculación al resto de los jueces, lo que en último término parece suponer la única justificación posible a tal excepcional extensión del límite subjetivo de la cosa juzgada. La sujeción en términos de "giudicato" de un juez, extraño al primer proceso, y que debe decidir la elevación de la cuestión de inconstitucionalidad al Tribunal, supone, a nuestro juicio, una difícil equiparación con la situación en que se encuentra el juez que resuelve una cuestión prejudicial devolutiva, y ni aún en esta situación se admite siempre tal vinculación en términos teóricos de cosa juzgada. No parece por otra parte que la labor del juez en este caso se ajuste especialmente a la rigidez del concepto de "giudicato", ni que concuerde con el espíritu y la jurisprudencia en torno al art. 5.3 de la LOPJ. Parece que en este campo nos moveríamos mejor en el ámbito de otros efectos de la sentencia mucho más relacionados con la labor hermenéutica, de la Constitución y de la ley, que la decisión sobre la proposición de la cuestión de inconstitucionalidad implica. No puede olvidarse tampoco que, ante un efecto tan "extraordinario" en un juicio no incidentalmente prejudicial, la expresa mención del art. 38.3 tan sólo al juez "a quo" no parece añadir argumentos a favor de una posible vinculación de "res iudicata" frente al resto de los jueces.

Por otra parte, semejante imposibilidad de elevar la cuestión de inconstitucionalidad queda supeditada al hecho de que el juez ordinario "no aprecie que se ha producido un cambio de circunstancias suficiente para modificar el sentido y el alcance de la norma constitucional utilizada como parámetro" "14. Sin embargo debe destacarse, en primer lugar, que la modificación del campo normativo infraconstitucional, cuya apreciación correspondería en exclusiva aquí al juez ordinario, podría suponer en buena lógica una mutación en el sentido de la ley objeto del juicio anterior, e implicar en consecuencia una falta de identidad entre "res iudicata" y "res iudicanda" que permitiría el replanteamiento de la cuestión de inconstitucionalidad o al menos justificaría que el juez ordinario elevara la misma a la consideración del TC.

En todo caso, y dado que en último término será el Tribunal Constitucional quien "sólo podrá admitir tales instancias si considera que dicha mutación ha podido acaecer "115, no parece necesario someter la elevación y la admisión de la cuestión a la posible existencia de un efecto de cosa juzgada apreciable en dos fases distintas y por dos órganos jurisdiccionales diferentes. Una valoración estricta por parte de la magistratura de esa "res iudicata" que la vincula, impediría precisamente el replanteamiento de las cuestiones de inconstitucionalidad y la apreciación por parte del Alto Tribunal de la necesidad o no de una evolución de la interpretación constitucional sobre la materia. Y esta valoración, que corresponde en exclusiva al Tribunal Constitucional, y que sólo es posible ante la elevación de cuestiones de inconstitucionalidad, es en definitiva una valoración sobre la existencia o no de los supuestos que dan

114. Op. cit., p. 350.

115. Op. cit., p. 350. 
lugar al efecto de cosa juzgada, efecto que en buena lógica debería afectarle en exclusiva. Es por todo ello por lo que quizás sea más útil una configuración del efecto de las sentencias que fuerce menos el núcleo conceptual del instituto, consiguiendo a su vez ser compatible con la reproposición de RI/CI y encontrando un mayor equilibrio entre prohibición de repetición y apertura a la evolución jurisprudencial. En definitiva, que explique conceptualmente por qué con determinados límites el juez ordinario puede replantear la duda constitucional, dentro de su genérica vinculación a la jurisprudencia constitucional, y por qué, en caso de considerar que existe identidad, el TC debe rechazar entrar a conocer del asunto al estar impedido para ello por el efecto de cosa juzgada de la sentencia anterior. 